\title{
أهمية وتطبيق فرق العمل في هجالات متنوعة \\ لتحقيق المستوى المثالي في الأداء
}

\section{IMPORTANGE AND APPLIGATION OF TEAM WORKING IN VARIABLE FIELOS TO ACHIEVE PERFECT PERFORMANCE}

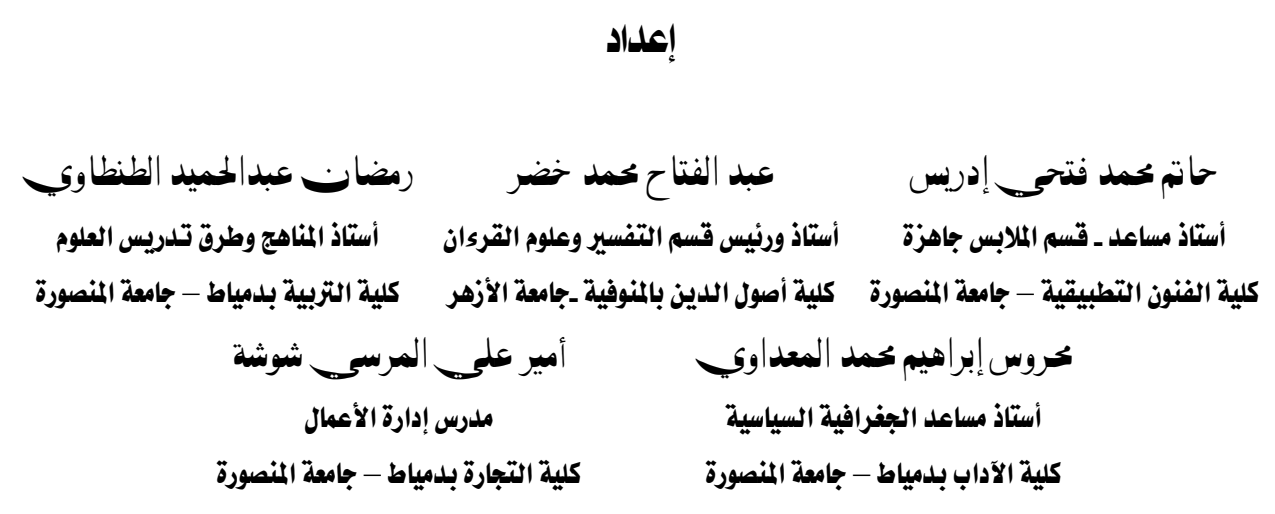

مجلة بحوث التربية النوعية - جامعة المنصورة

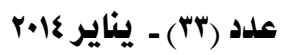




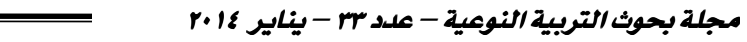

\section{أهمية وتطبيق فرق العمل في هجالات هتندوعة لتمقيق المستوى المثالي في الأداء}

إعداد

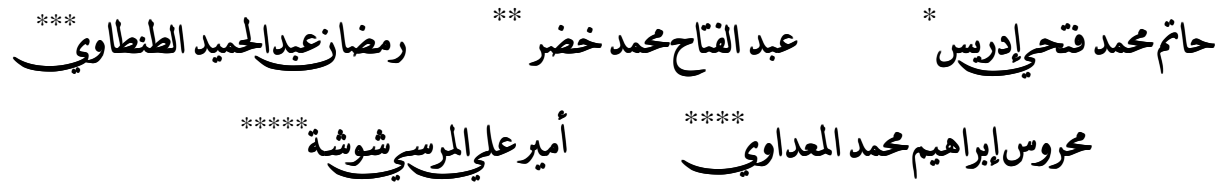

\section{هلخص البحث}

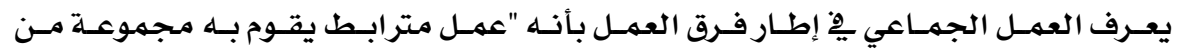

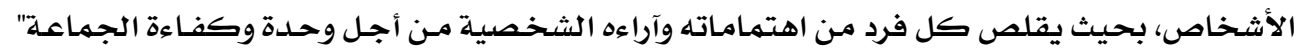

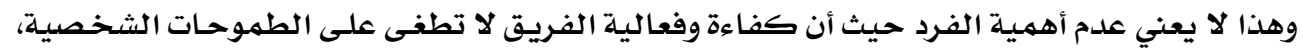

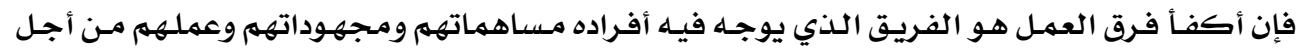
هدف مشترك.

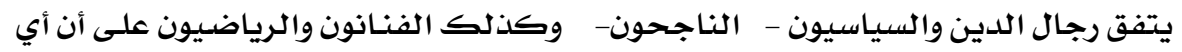

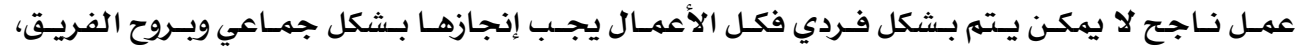

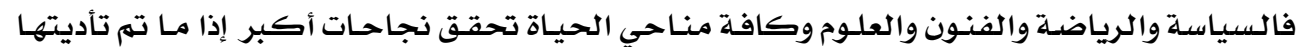

$$
\text { بروح الفريق. }
$$

ويهدف هذا البحث إلى التأكيد على أهمية العمل الجمـاعي يِّ إطـار فرق العمل وأفضليته

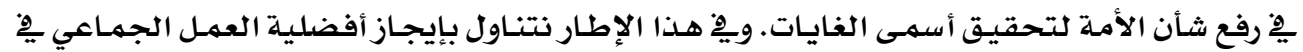

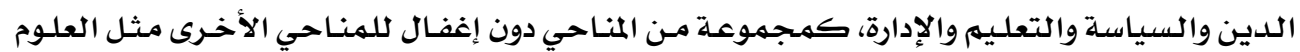
والفنون والرياضـة ... الخ.

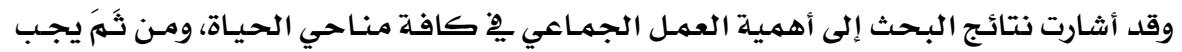

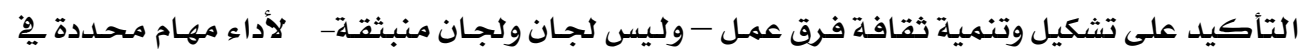

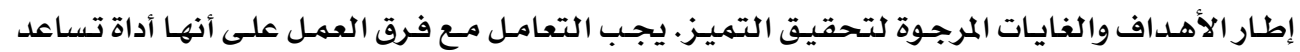

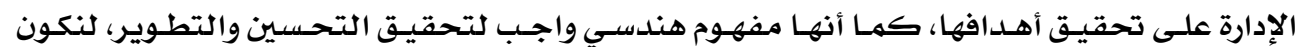
معاً أفضل.

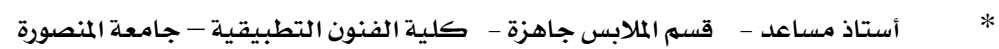

** أستاذ ورئيس قسم التفسير وعلوم القرءان - كلية أصول الدين بالمنوفية - جامعة الأزهر

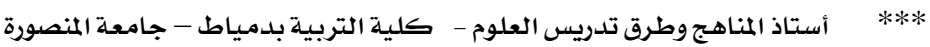

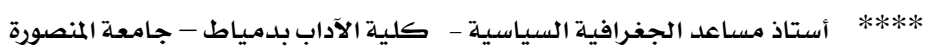

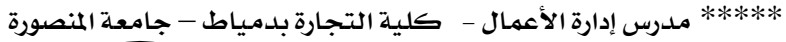




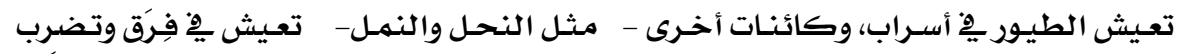

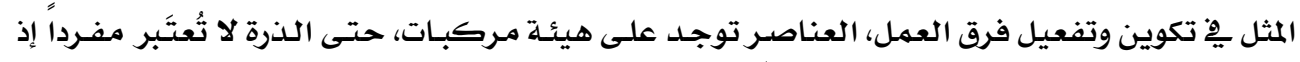

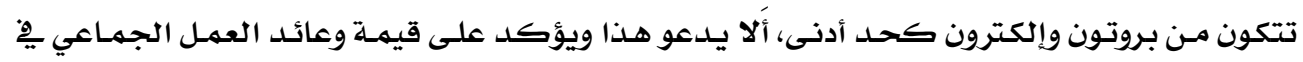
إطار فرق العمل.

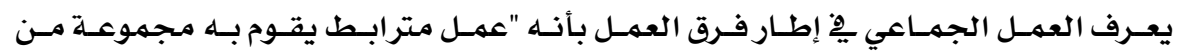

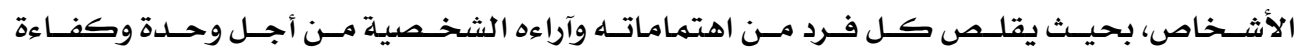

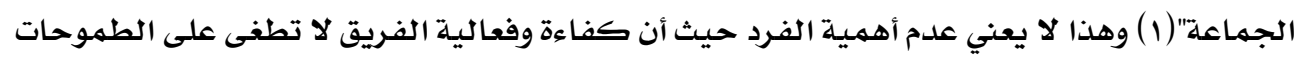

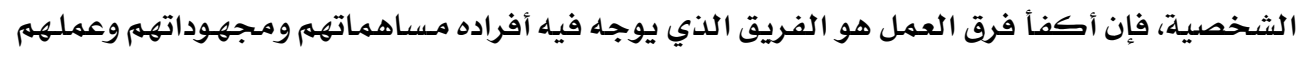
من أجل هدف مشترك.

تتفق الأديان والسياسيون -الناجحون- وكذلك الفنانون على أن أي عمل ناجـح لا يمكن

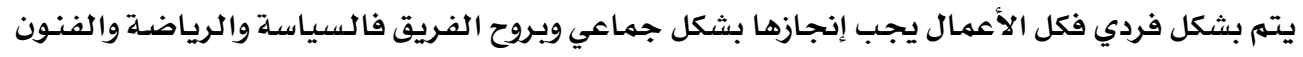

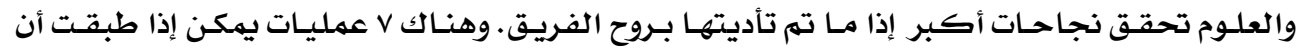

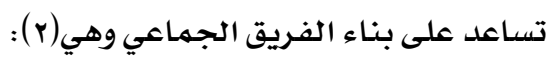

الدعم: تقديم الدعم والتشجيع لعضو الفريق يِ حالة الاتفاق والاختلاف.

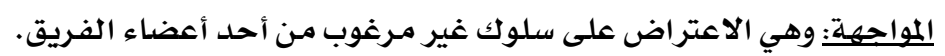

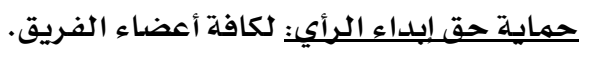

الوساطة: عندما تصبح المناقشات مكثفة مطولة.

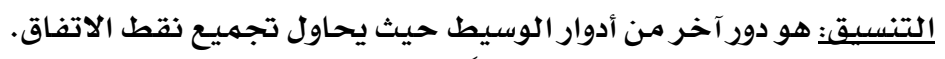

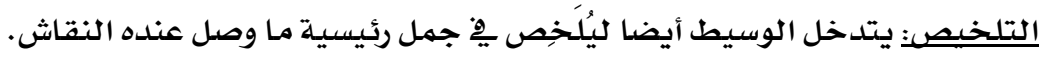

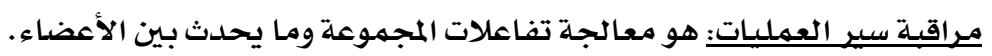

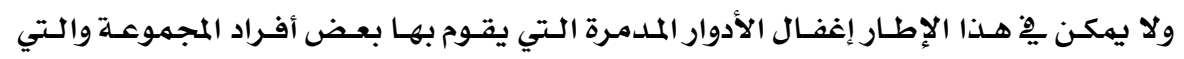

تتمثل بِ2:

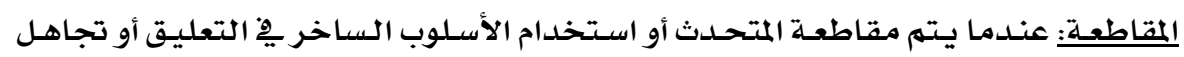
باقي المجموعة لمساهمة أحد الأعضاء.

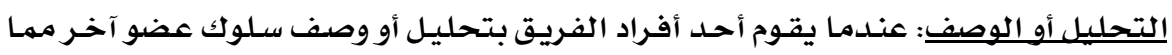

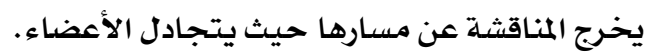

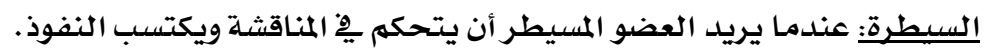

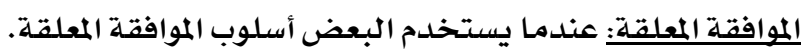

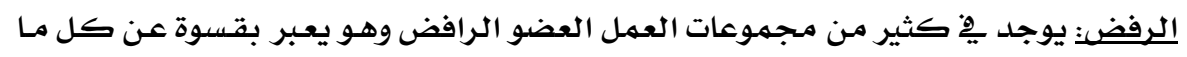




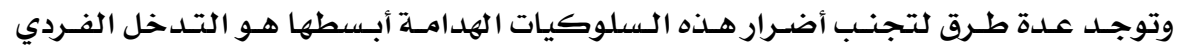

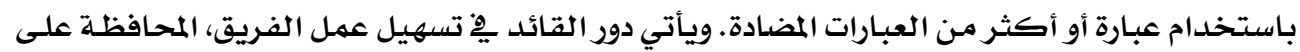

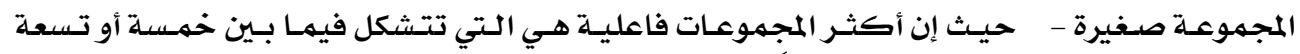

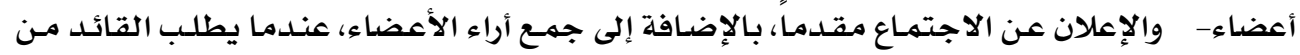

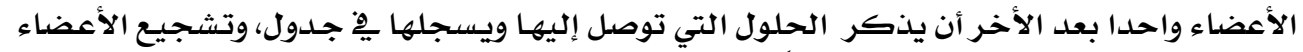

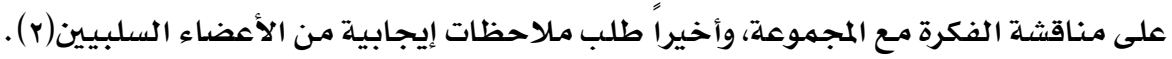

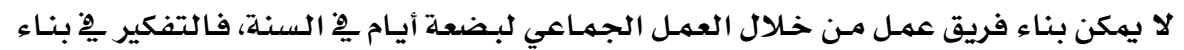

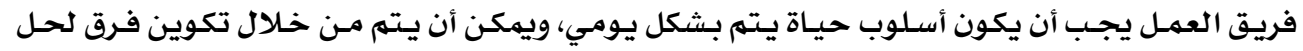

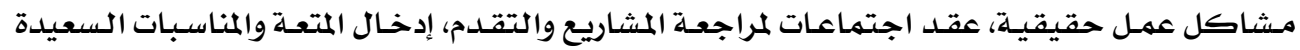

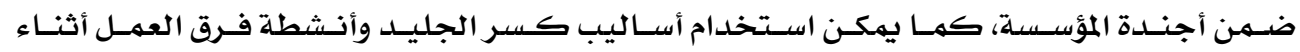

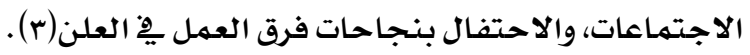

\section{مشكلة وتساؤل البحث:}

تتركز مشكلة البحث ِِّ إنتشار الفردية والأنانية والمغالبـة ِِّ مجتمعنا، وافتقـاد روح الفريق

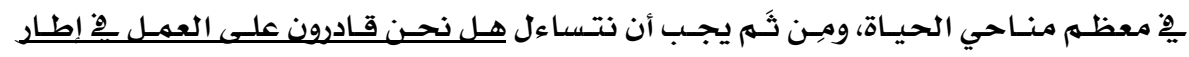

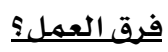

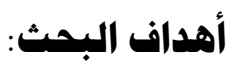

يهلدف هذا البحث إلى التأكيد على أهمية العمل الجماعي يِّ إطار فرق العمل وأفضليته ِِِ

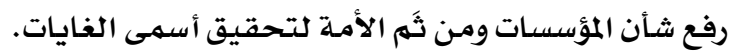

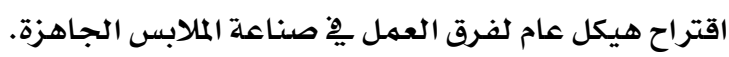

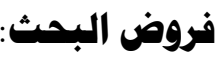

تتفق محساور الدين والتعليهم والسياسـة والإدارة على أهميـة وقيمسة وأفضلية العمل ِِِ إطـار

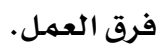

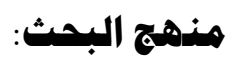

يتبع البحث المنهج الوصفي، المنهج التحليلي والمنهج التجريبي لتحقيق أهداف البحث.

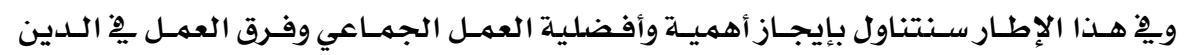

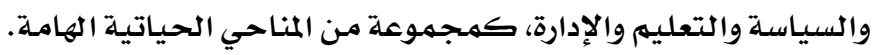
r- برق العمل في الدين

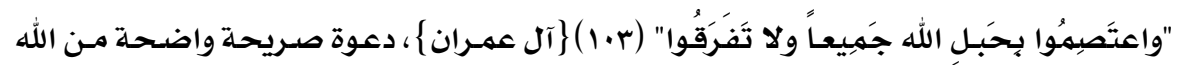

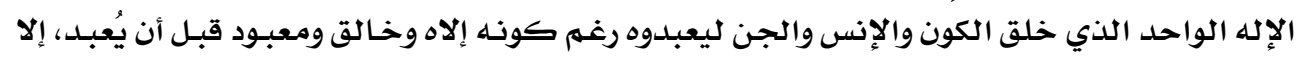




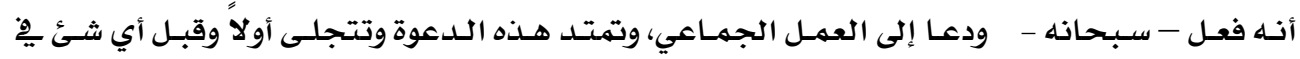
الدين ومناسكه.

ففي المسيحية نجـــ أن الكنيسـة أخسذت كلمـة "ليتورجيـا" وأطلقتها على حياتها ونظامها،

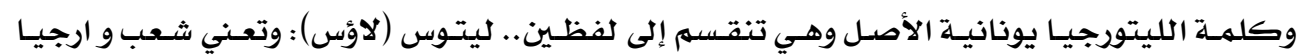

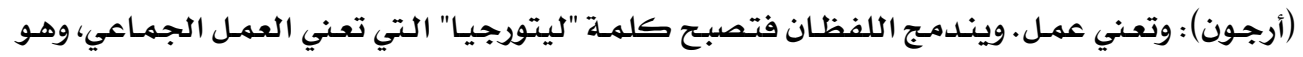

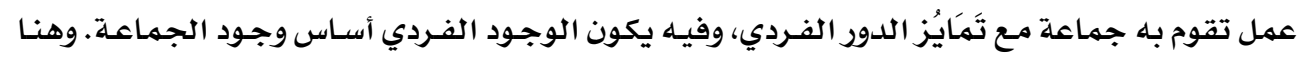

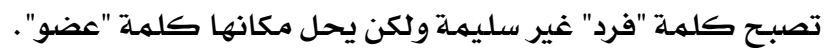

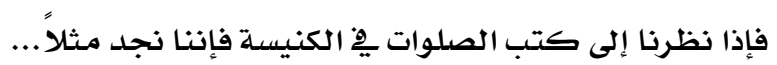

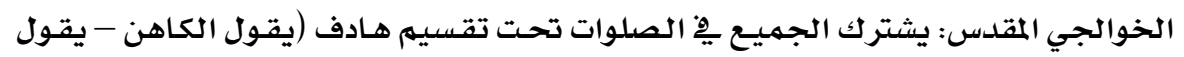

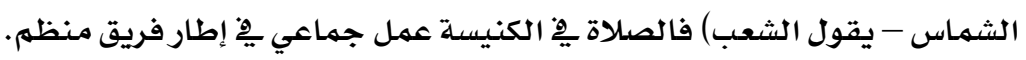

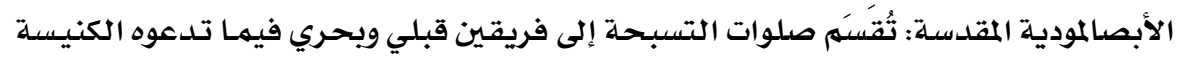

$$
\text { "خورس" قبلي وآخر بحري. }
$$

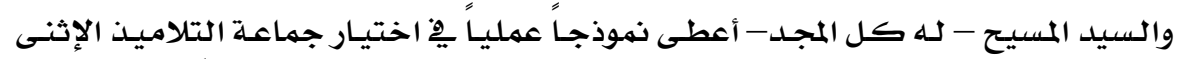

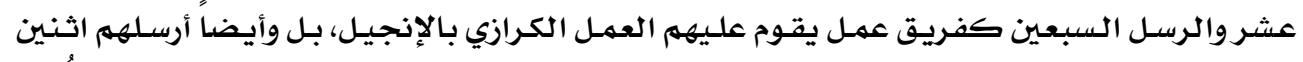

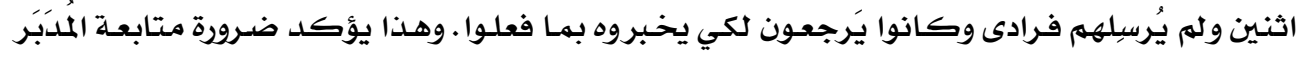

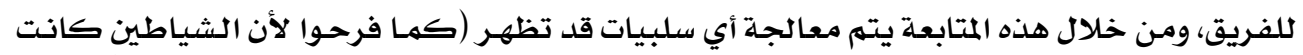

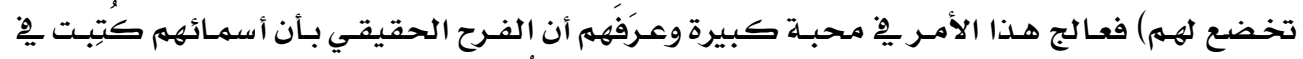

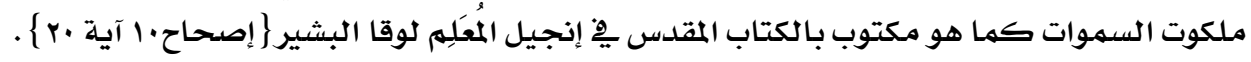

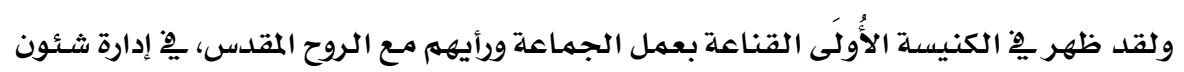

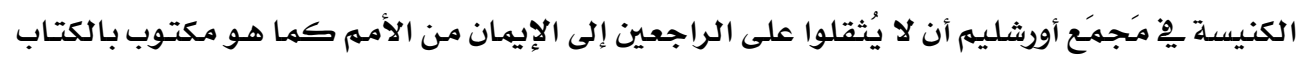

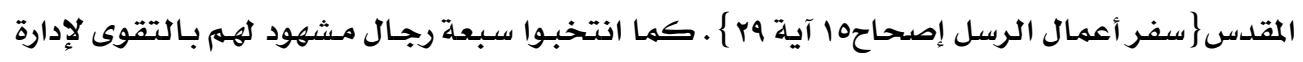

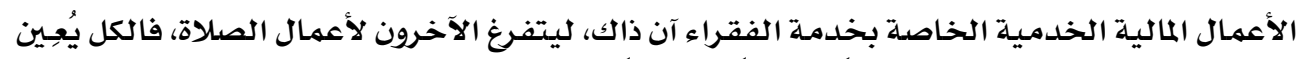

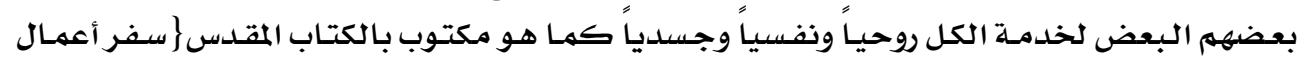

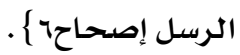

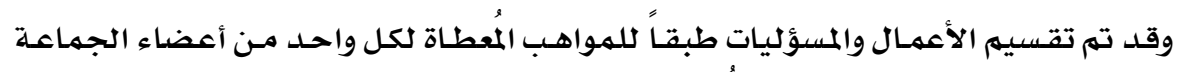

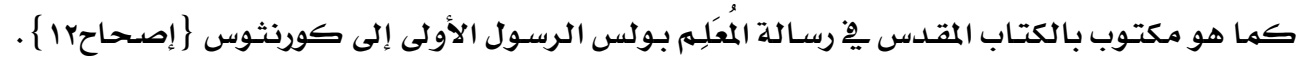

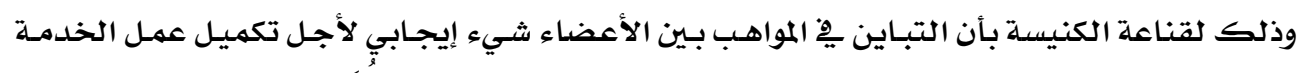

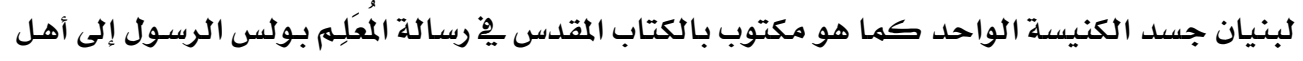

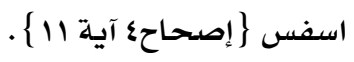

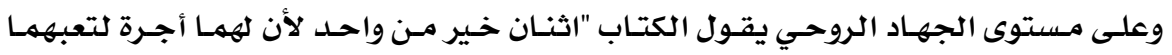

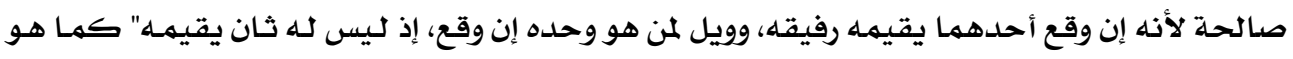




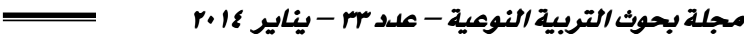

مكتوب بالكتاب المقدس \}سفر الجامعة إصسحاحع آيـة و و.1 \{. . فالجميـع يحتاج إلى آخر والآخر يحتاج إلى الجميـع للبنيـان.

وللعمل الجماعي يِ الإسلام أهميته وقيمتهه، إذ هو عمود الإسـالاموجوهره لذلك نجد الحـث

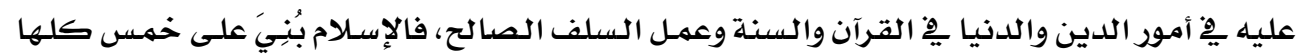
أعمال جماعية.

الشهادة هي قول واعتراف بوحدانيـة الإلهه، إلا أنها عهل يتمر فيه الاعتراف من الفرد بإِله واحد

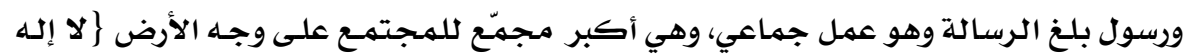

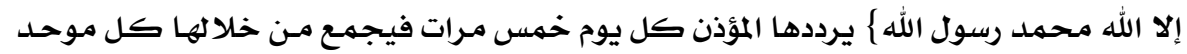
يريد أن يجدد انتماءه لله تعالى.

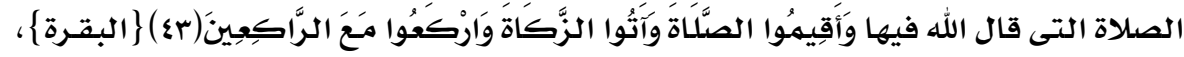

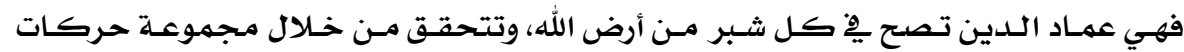
وكلمات من المسلمه، إلا أنها بشكلها الجماعي تزيلـ سبعا وعشرين درجه وهذا فيـه مـا فيـه مـن الترغيب يخ الجماعات، ونجد الجمـع وأيام العيد والجنائز، كل ذلك بأوامـر الله تعـالى لنزداد بهذه المظاهر التعبدية قوة ومنعـة واجتهماعاً. كما نلمس العمل الجماعي يخ الزكاة التي تهثل التكافل الجمعي بين المسلمهين حيث جعلها

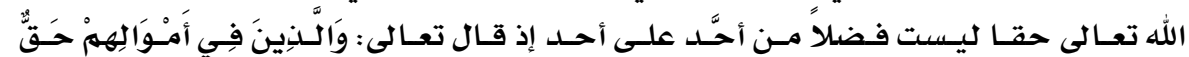

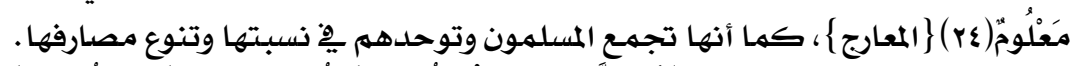

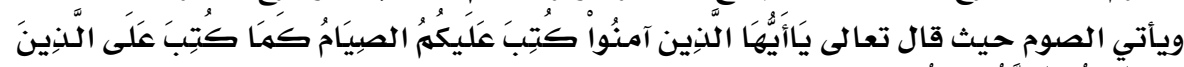

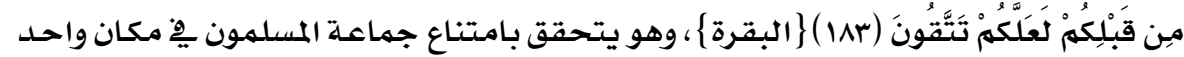

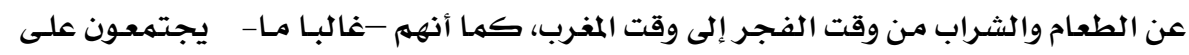

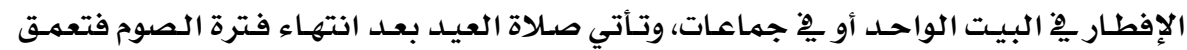
رؤيـة العمل الجمهاعي.

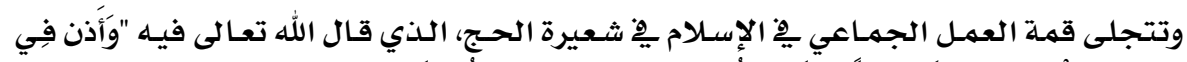

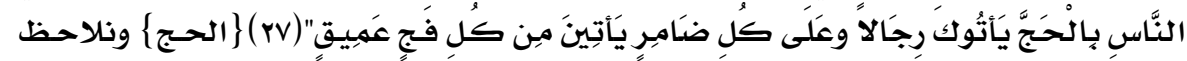

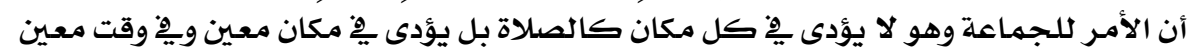

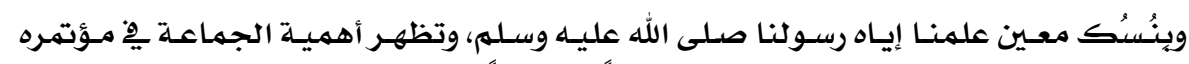

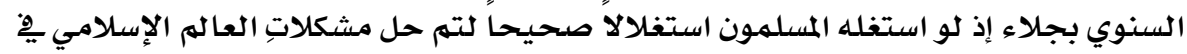
كل موسهم من مواسمه ولسعد أهل الإسلام والناس أجمعين.

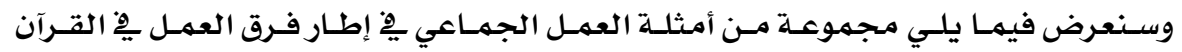
والسنـة والسيرة: وسيرة

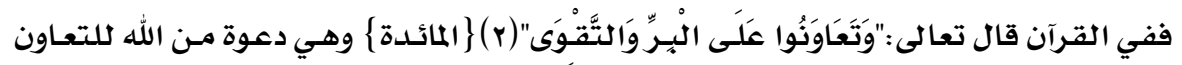

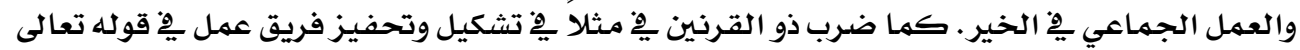




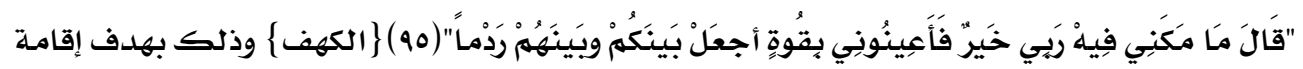

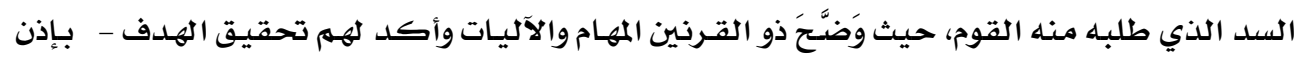
الله- إذا أدى كلّ منهم دوره.

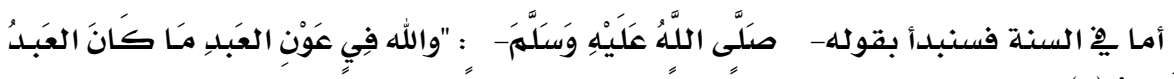

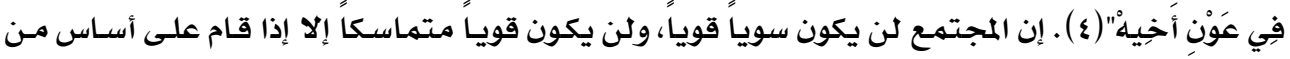

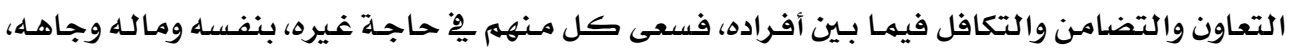

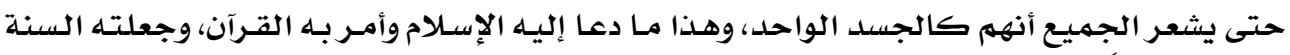
المطهرة عنوانا لمجتمـع الإيمان.

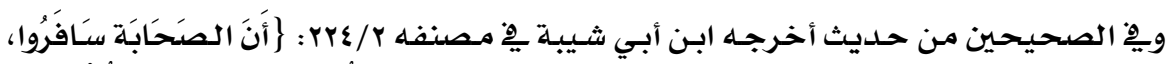

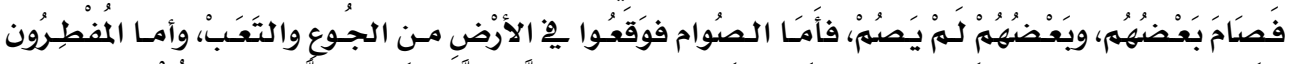

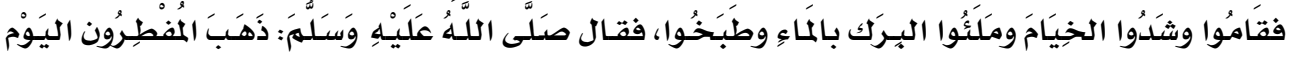

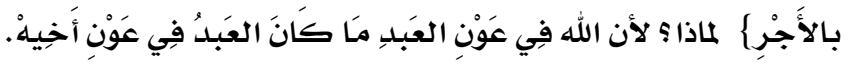

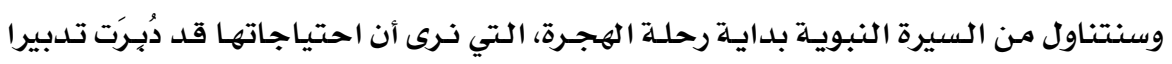

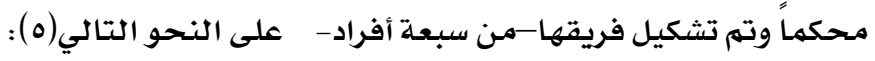

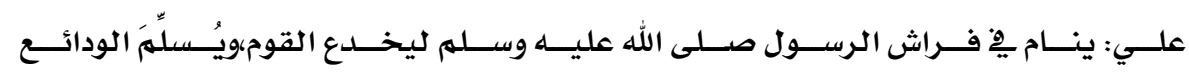
ويلحق بالرسول.

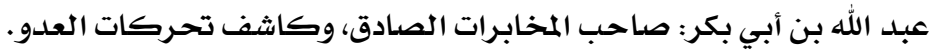

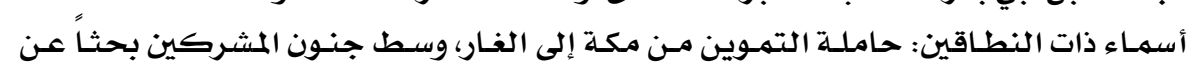
محمد صلى الله عليه وسله ليقتلوه.

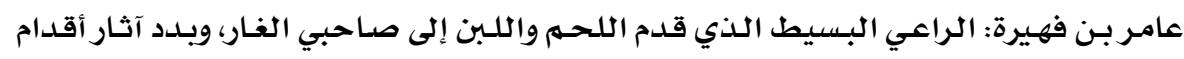

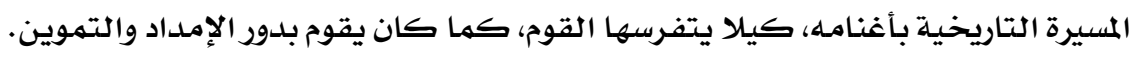

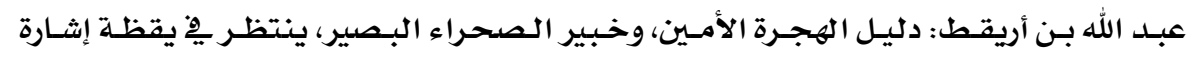

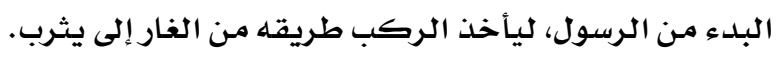

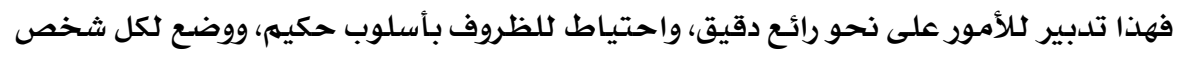

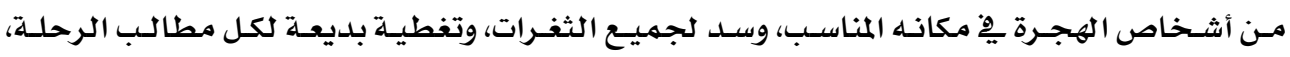

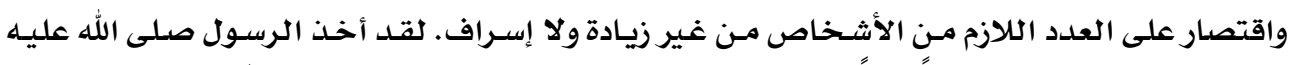

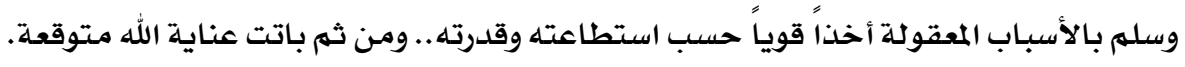

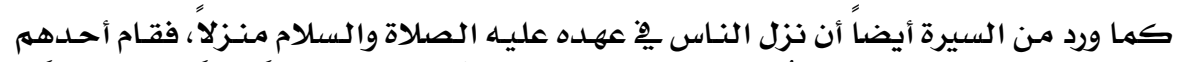

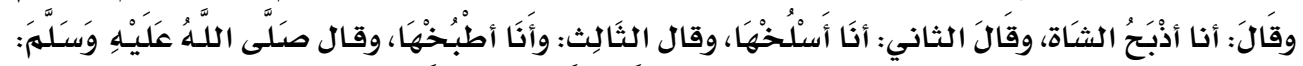

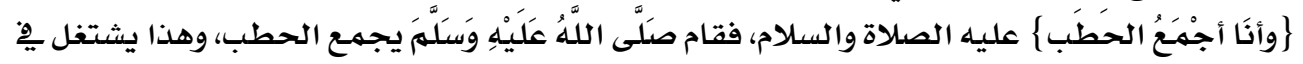

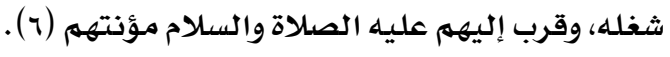


وأخسيرا نحسن ِِّ الحيـاة أسـرة إنسانية واحسده لـو تركنـا بعضنا دون ترغيـب وترهيـب وبشارة

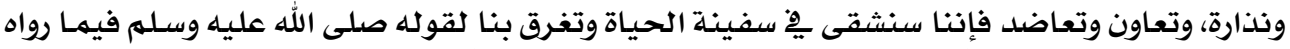

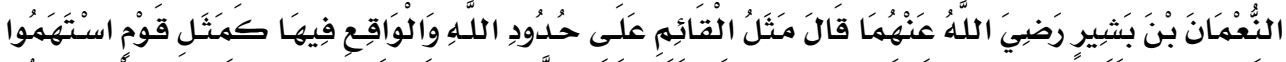

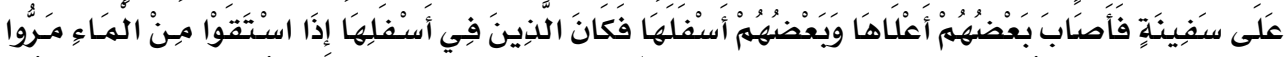

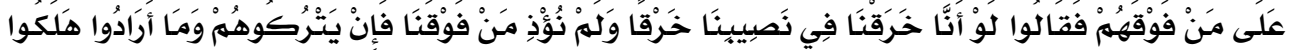

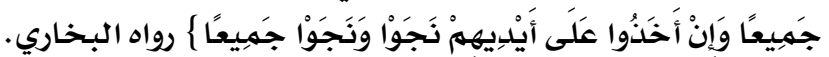

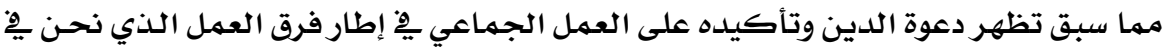

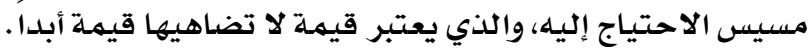

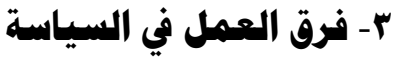

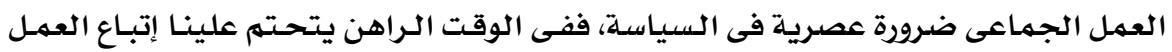

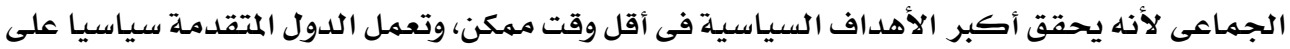

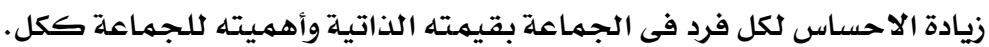

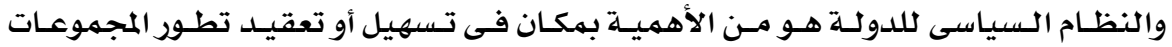

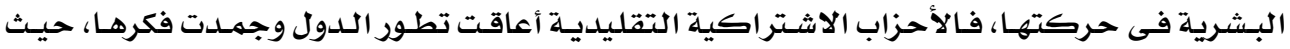

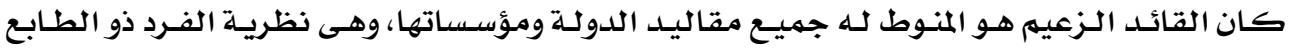

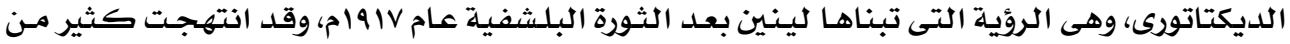

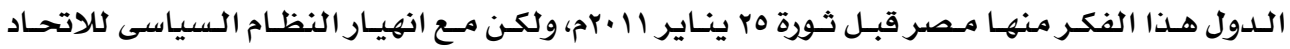

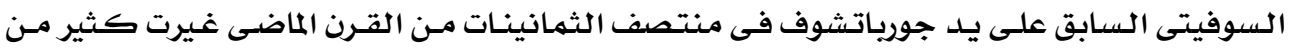

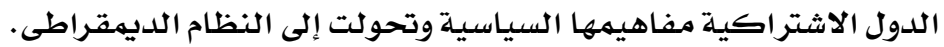

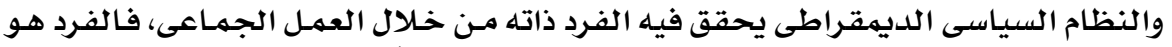

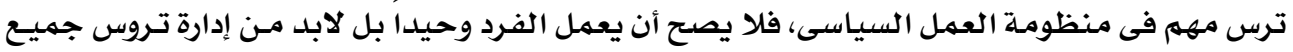
الأفراد حتى يتحقق الهدف الديهقراطى في ملف النهاية.

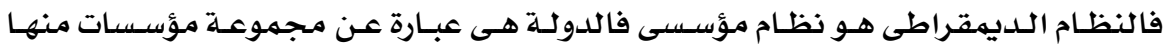

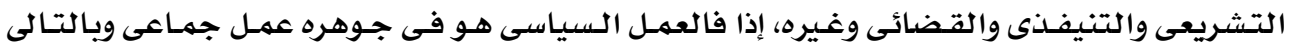

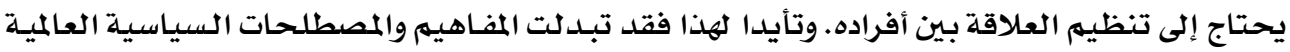

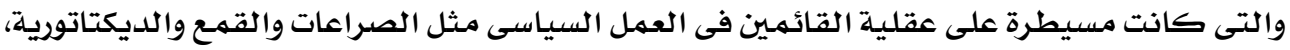

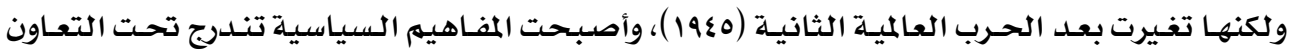

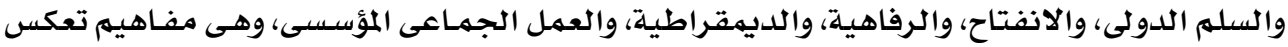
تحول المجتمع الدولى إلى تحقيق التقدم والازدهار لشعوبها (v). 
فالنظام الديهقراطى مبنى على رأى الجماعة (الشعب)، إذا فالعمـل الجمـاعي يختار رئيس الديس

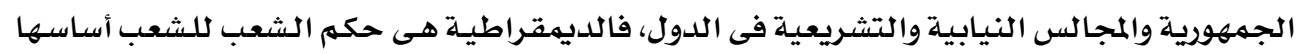
التعددية الحزبية.

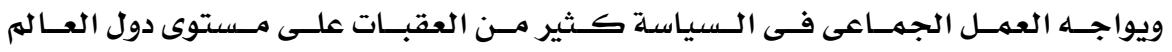

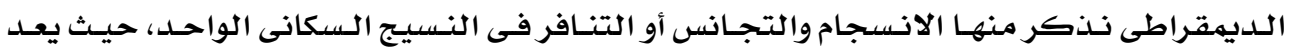

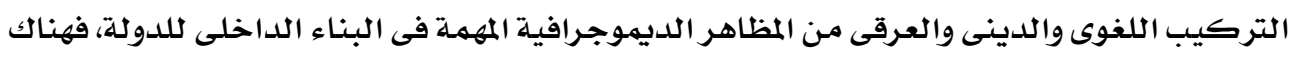

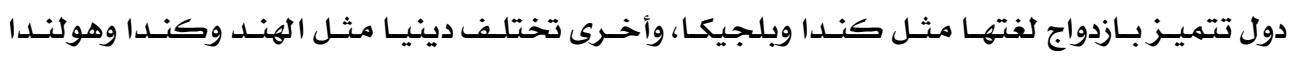

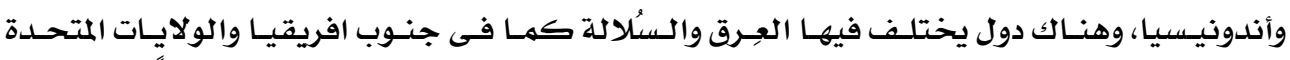

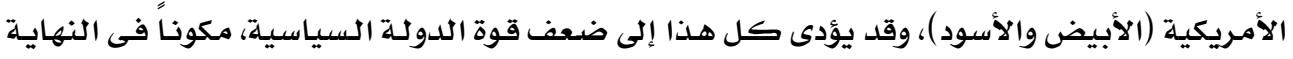

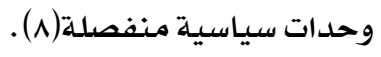

ويتطلب حل تلك المشكلات وضع قوانين ملزمـة تطبق بعدالة على جميع فئات المجتمـع يكون

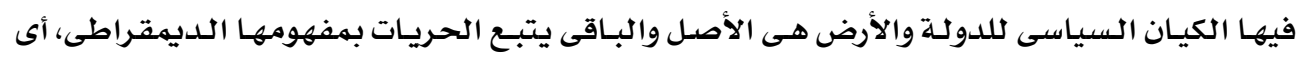
أنها حريات مقيدة بقوانين منظمة وملزمة النسيان.

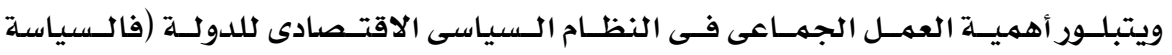

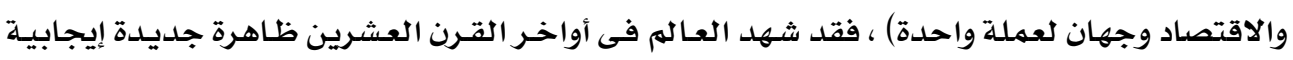

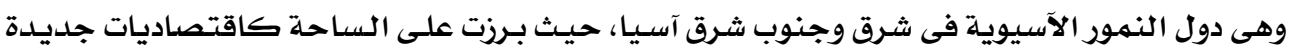

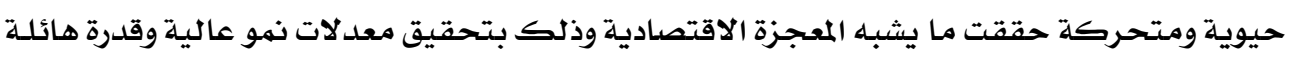

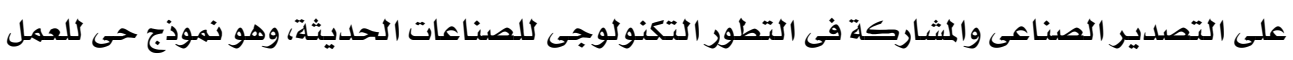

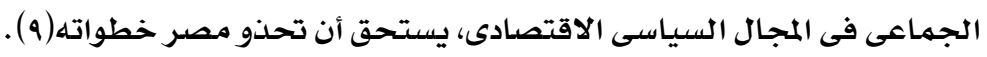

\section{ع- فرق العمل في التعليم}

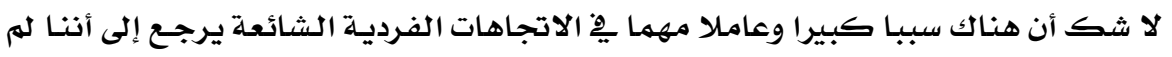

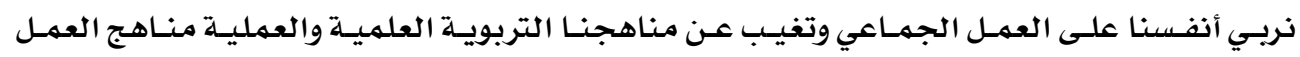

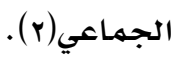

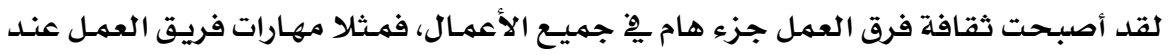

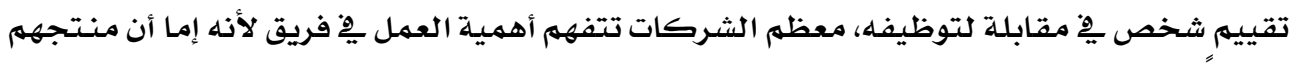

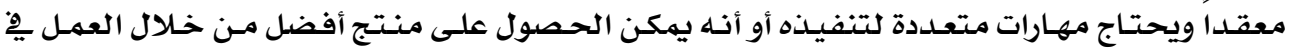

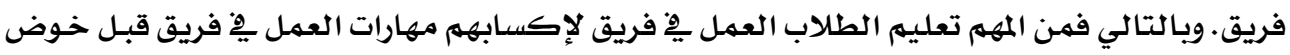

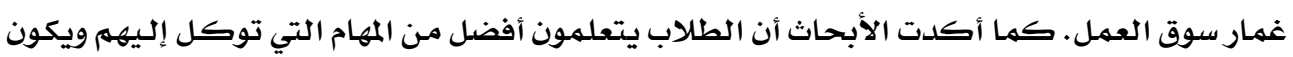
فيها مشاركة مجتمعية(. (1).

بُذلت مجهودات كثيرة ِِِ بحوث ودراسات نفسية وتريوية تبحث عن تدريس فعال بعيداً. ولما

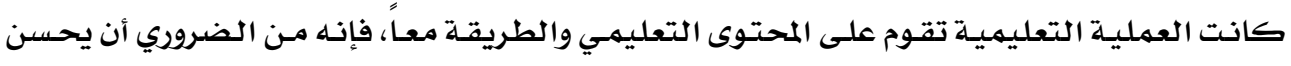


المعلم اختيـاره لطريقـة تدريسـه وكذلك اختياره للأنشطة والوسـائل المناسبـة التي تسههم فِ تحقيق الأهداف المرجوة.

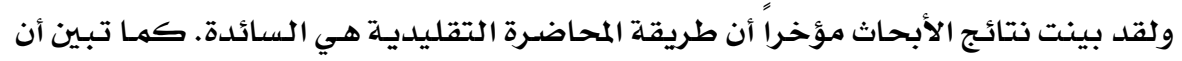

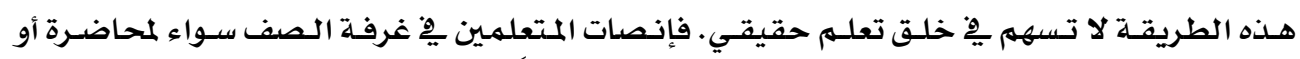

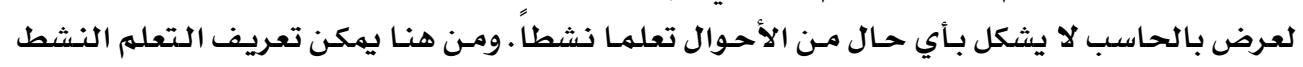

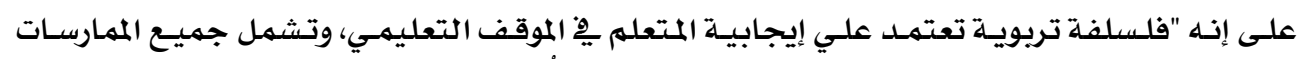

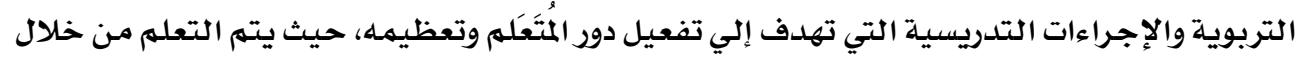

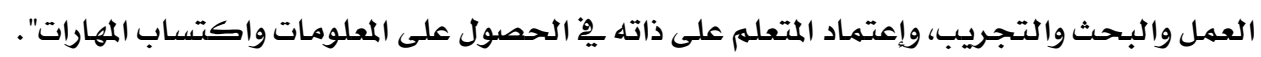

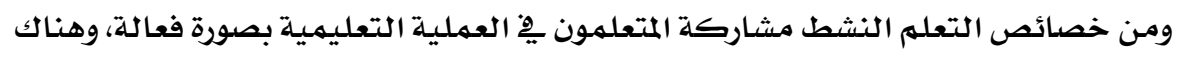

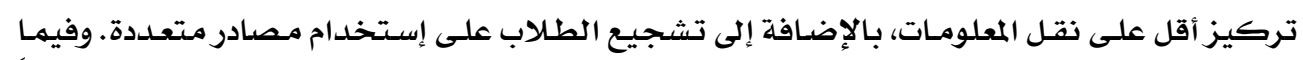

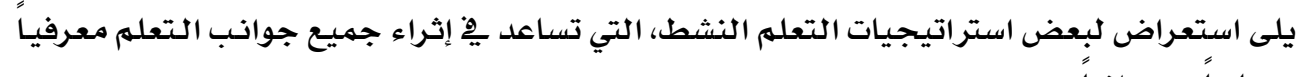
ومهارياً ووجدانياً.

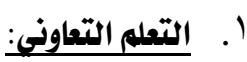

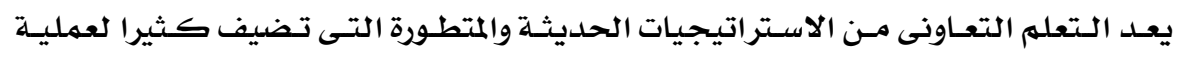

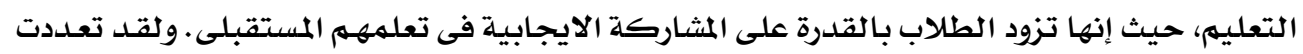

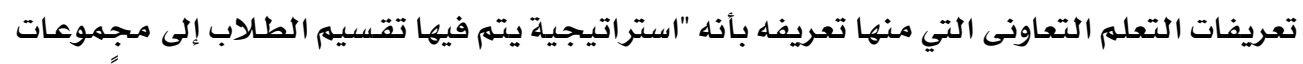

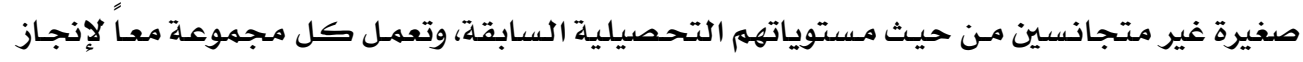

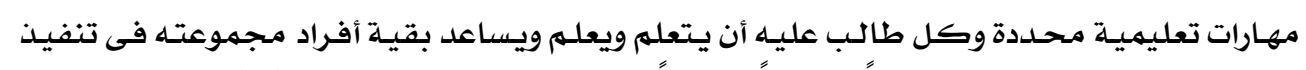

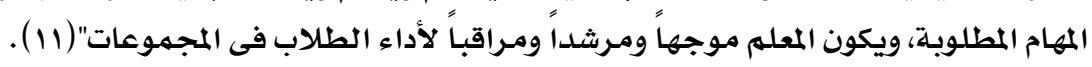

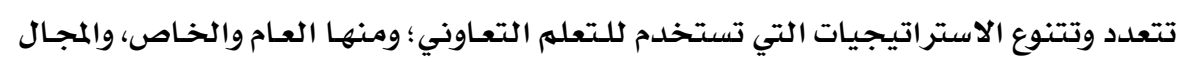

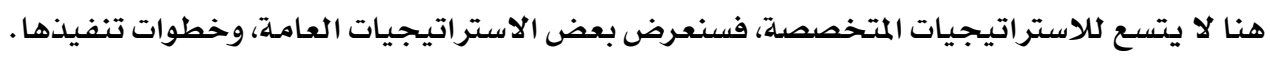
أ- ترتيب المهام المتقطعة: وتقوم على تقسيم الطلاب إلى مجموعات صغيرة من (r- م ه) طلاب،

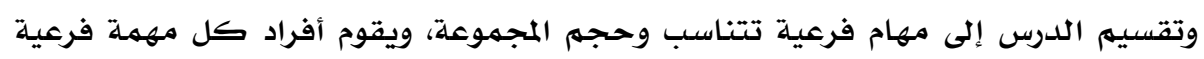

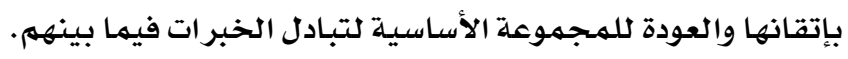

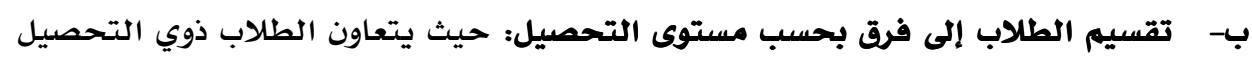

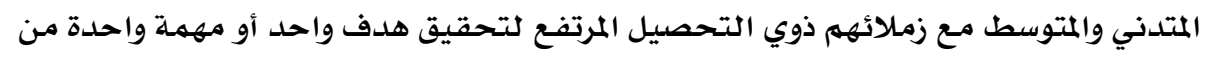
مهام التعلهم.

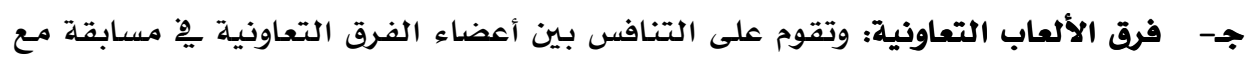

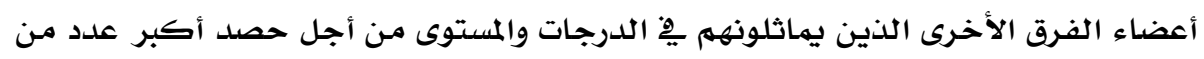
النقاط لفريقهم.

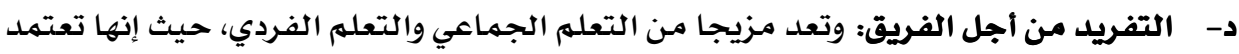

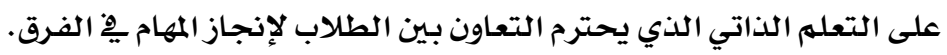




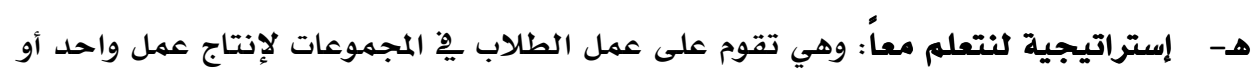

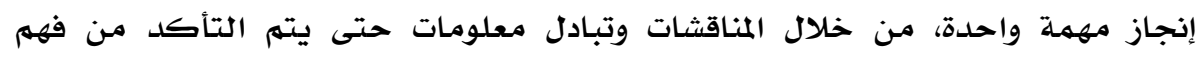
المادة التعليمية. - مان.

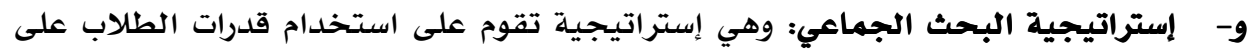

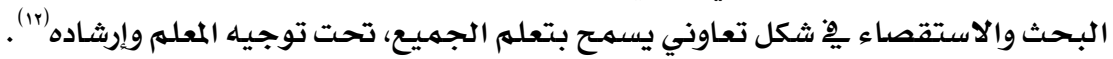

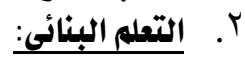

تُعتبر البحوث التى أجراها عاله النفس "جان بياجيه" في نمو المعرفة وتطورها عند الانسـان

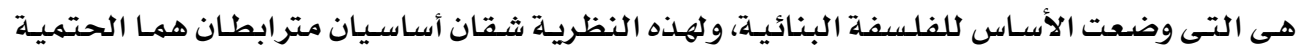

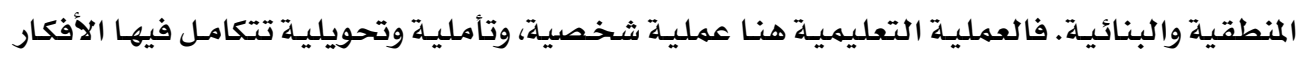

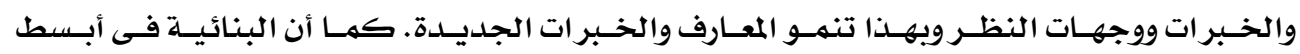

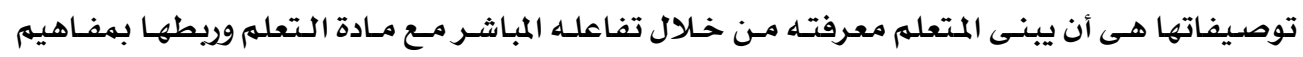

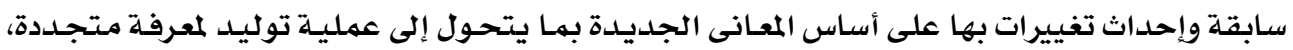

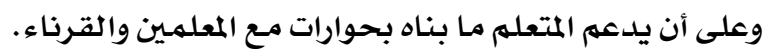

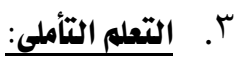

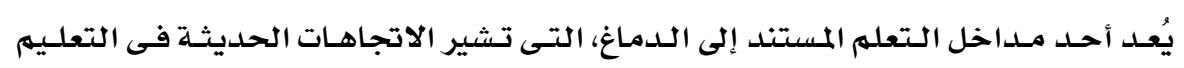

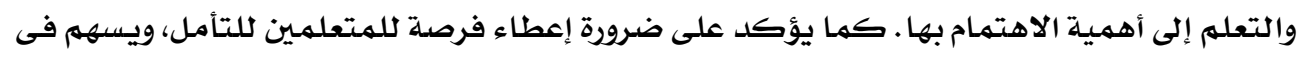

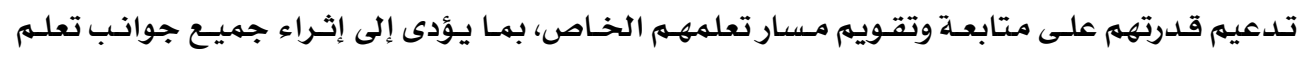

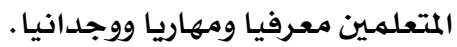

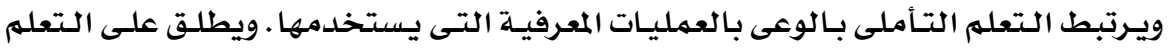

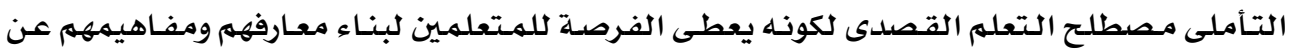

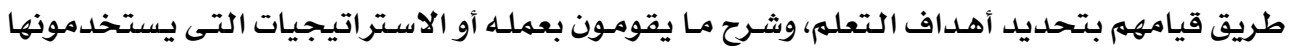

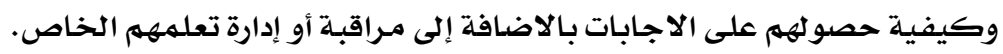

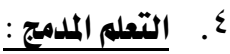

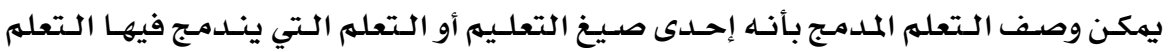

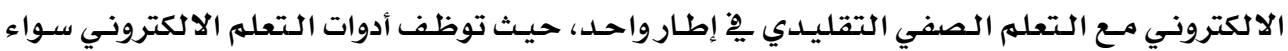

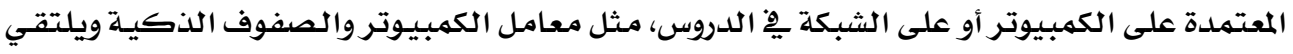

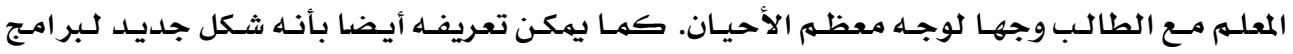

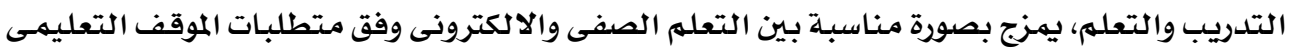
بهدف تحسين تحقيق الاهداف وبأقل تكلفة ممكنة.

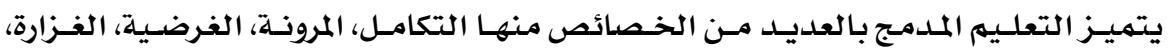

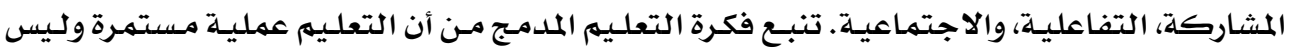




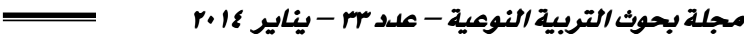

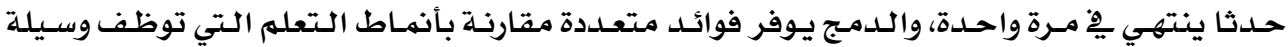
اتصال واحدة(r) )

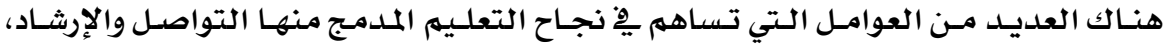
العمل التعاوني على شكل فريق، تشجيع العمل المبهر الخلاق، والاختيارات المرنة. •.

يقوم المبدأ الرئيسي للتعلم المتمايز على أن التعلم لجميع الطلاب بغض النظر عن مستوى مهاراتهم أو خلفياتهم، وهو يفترض أن كل غرفة صف تحوي طلاب مختلفين يِ قدراتهم الأكاديهيـة

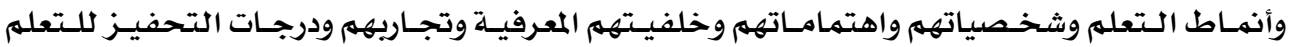
لـديهم. يهـلـف هـذا النـوع مـن التعلهم الى رفع مسستوى تحصيل جميـع الطـلاب بـاختلاف مسستوياتهم.

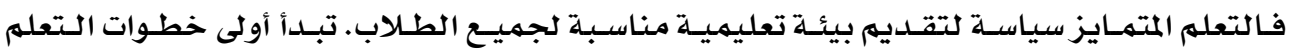

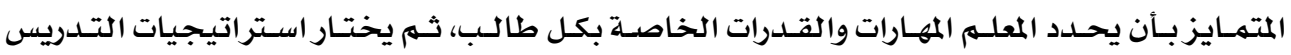
الملائمهة لكل طالب أو لكل مـجموعـة، وأخـيرا يحـدد المهام التى سـيقوم بها الطـلاب لتحقيـق الأهــاف.

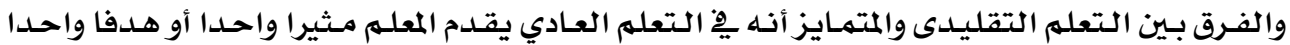

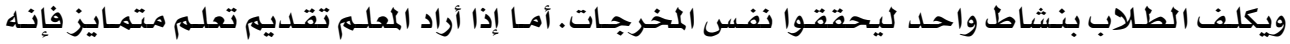
يقدم نفس المثير ومهام متتوعة ليصل إلى نفس المخرجات. ويتخذذ التعلهم المتمـايز عدة أشـكال متعـددة

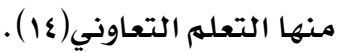

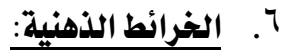

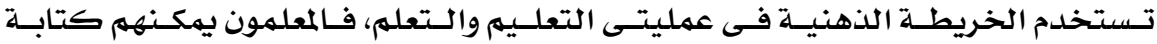
مـحاضـراتهم بـشكل خريطــة ذهنيـة تـسـاعدهم فى عـرض الأفكـار وتوضـيـحها ـ كمـا يهكن أن يـدريوا طلابهـهم على طريقـة إعـداد الخريطـة الذهنيـة، مـن خـلال إعـداد خريطـة ذهنيـة للكتـاب. ويستطيع

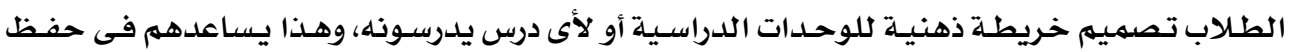
المادة الدراسية وسهولة تذكرها، سهولة مـراجعتها فى أيى وقت وبزمن قصير، سهولة ريطها بهوضوعات أخرى، وسهولة إضـافة معلومات جديدة فى أى وقت.

ومسن ثَم يهكن تعريـف الخريطـة الذهنيـة بأنها "وسـيلة يستخدمها الـدماغ لتنظيهم الأفكار

وصـياغتها بـشكل يسـهـح بتـدفق الأفكارويفـتح الطريـق واسـعا أمـام الـتفكير الإثـعاعى (وهـو انتشار الأفكار من المركز إلى كل الاتجاهات)" (10). : V

يستخلدم مـصطلح Brain Storming مـن قِبَل البـاحثين والمتخحصصين مـرادفا لعـدد مـن المفـاهيهم والمصطلحسات، ومنها القصف الدهنى، إمطسار الدماغ، تـفقق،أو توليد الأفكار، إلا أن مصطلح

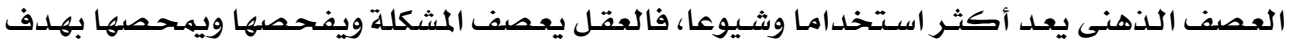

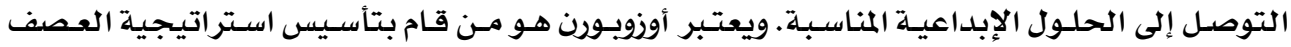
الـذهنى، وطورهـا فى كتابــApplied Imagination، والـذنى ظهـر فـى طبعتـه الأولى عـام 190V. 


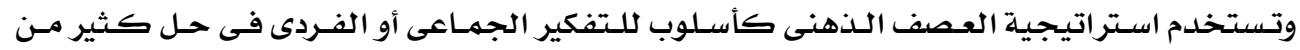

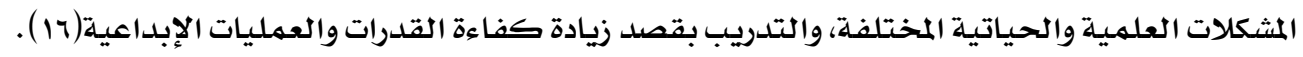
يعتمد استخدام استراتيجية العصف الذهنى على مبدأين أساسيين هما تأجيل الحكمه على الكى

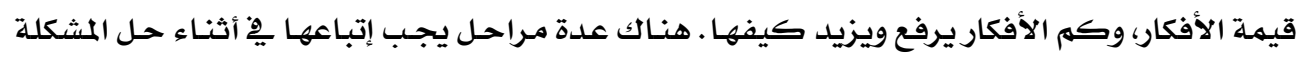

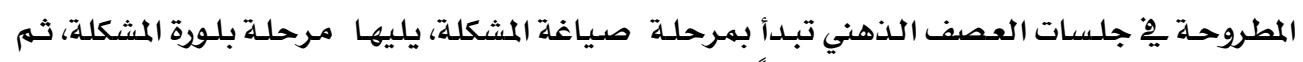

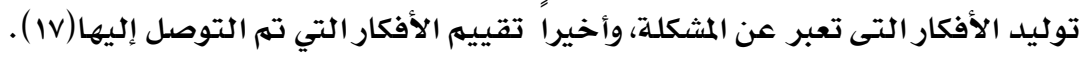

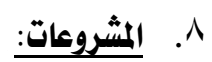

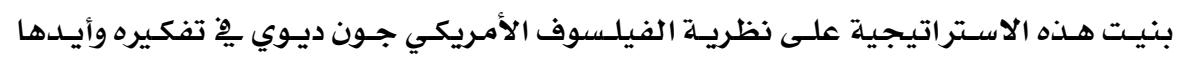

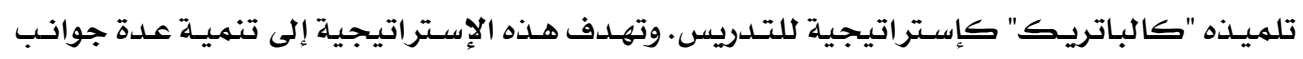

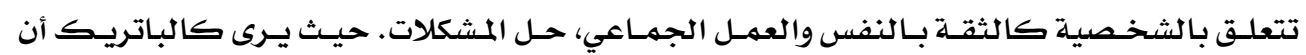

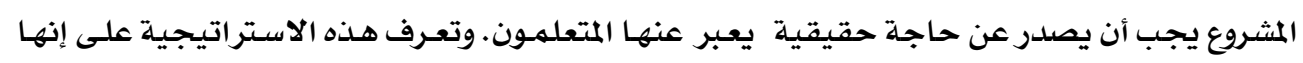

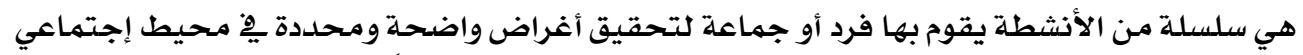

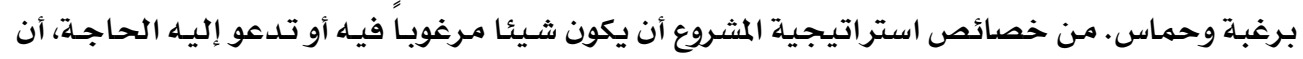

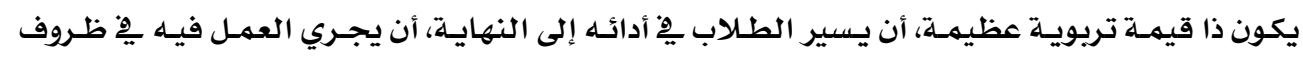

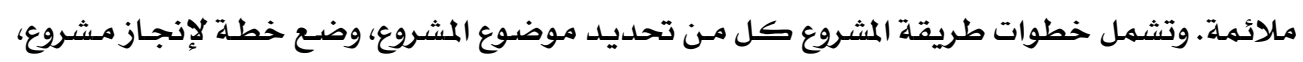

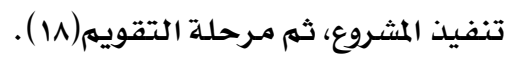

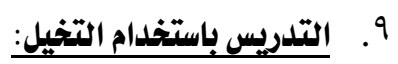

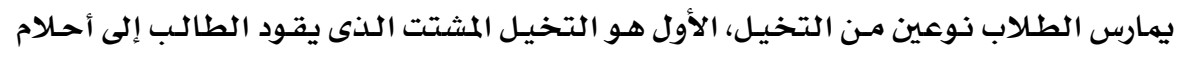

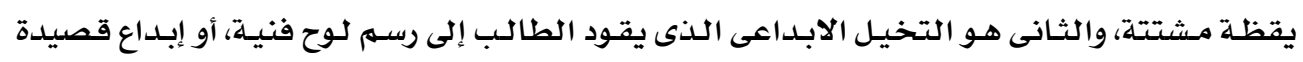

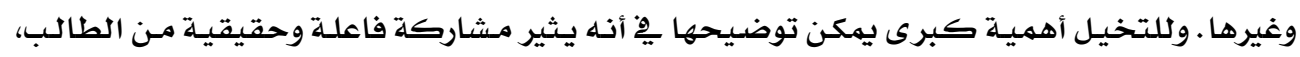

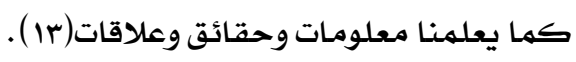

\section{0- - فرق العمل في الإدارة}

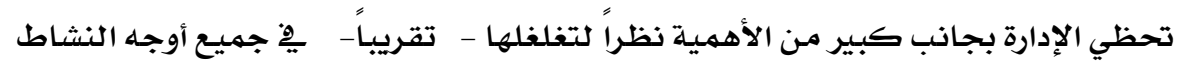

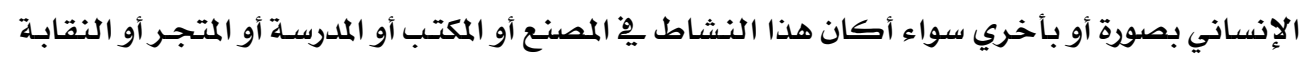

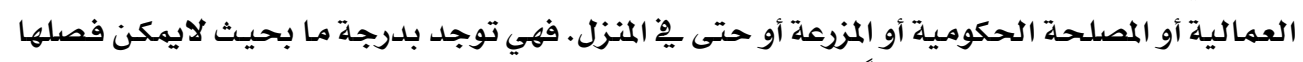

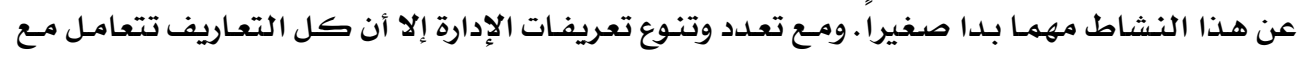

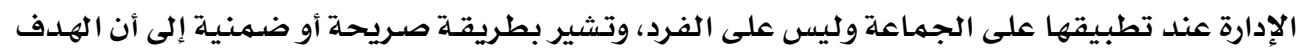

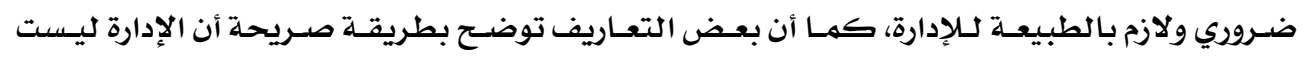

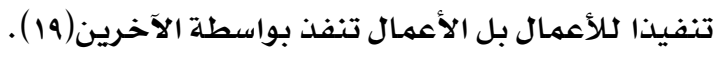

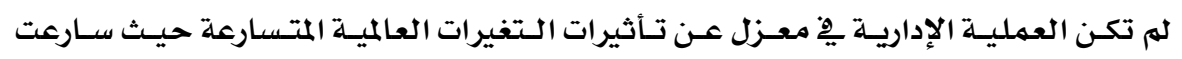

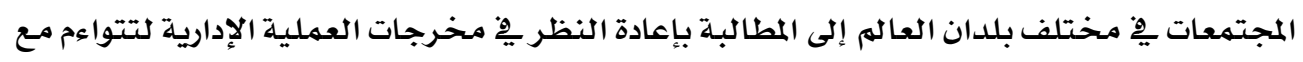


متطلبـات المراحل الحالية والمستقبلية. ولقـد سـاهم التطور الإداري ِِّ التركيز على العنصر البشري

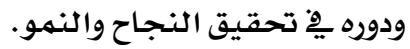

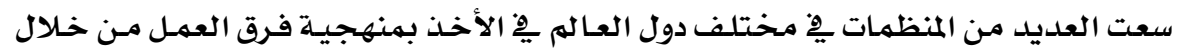

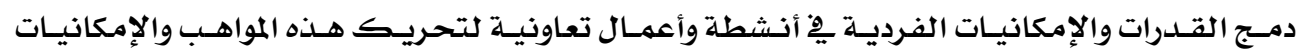

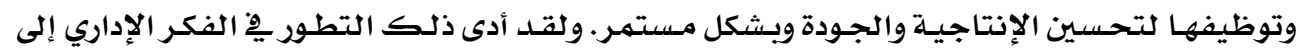

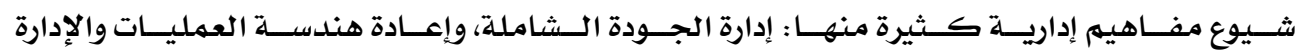

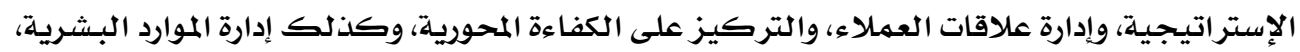

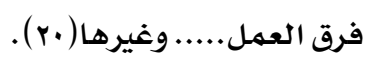

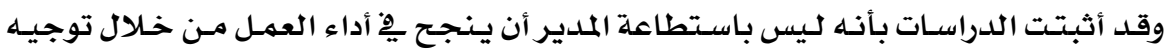

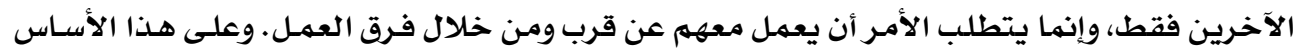

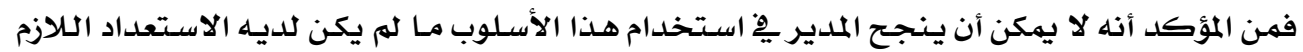

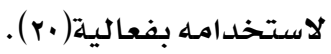

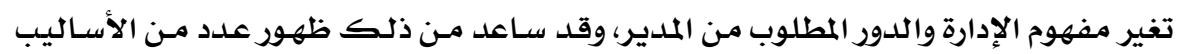

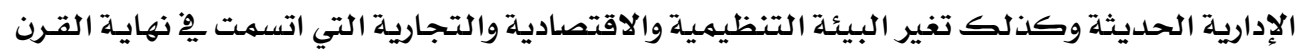

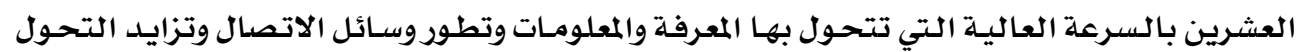

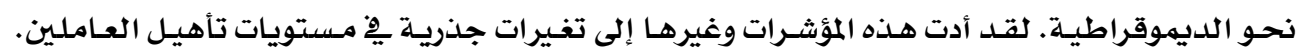

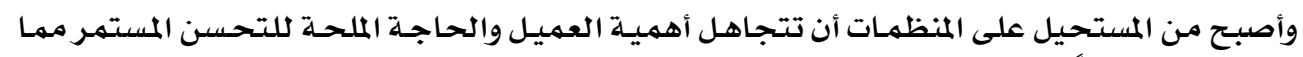

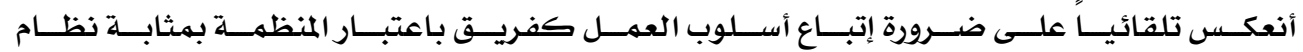

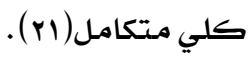

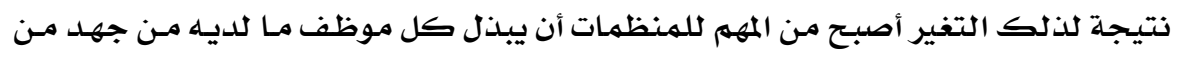

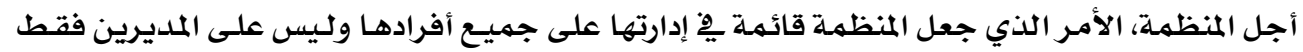

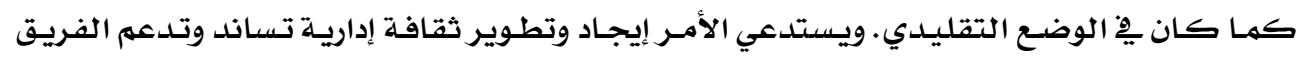
وتنمي المسؤولية الجماعية.

هناك العديد من الأعراض والمشكلات التي توحي بوجـود حاجـة ملحسة داخل المنظمسة للأخـذ

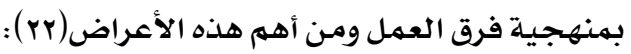

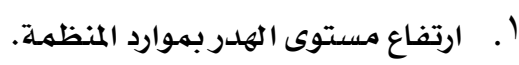

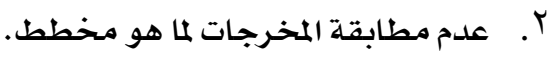

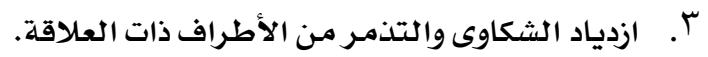
ع. انخفاض الروح المعنوية للأفراد داخل المنظمهة. 
عرف جابلونسكي إدارة الجودة الشاملة على أنها استخدام فرق العهل ِِّْ شكل تعـاوني لأداء

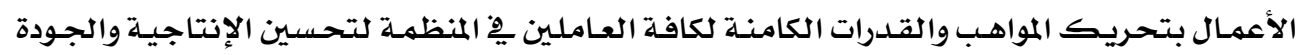

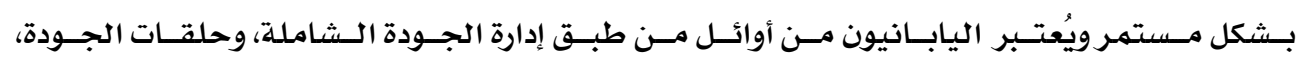

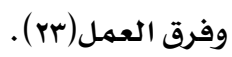

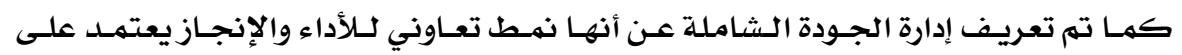

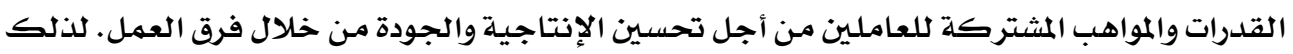

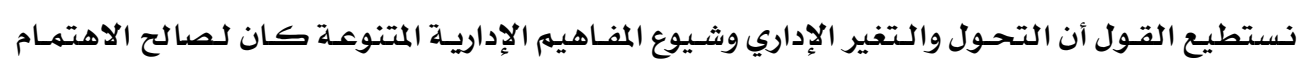
بالعنصر البشري والاهتمام به كعضو التحول ينتمي إلى فريق عمل يتسمى بالتعاون.

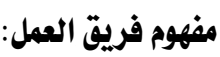

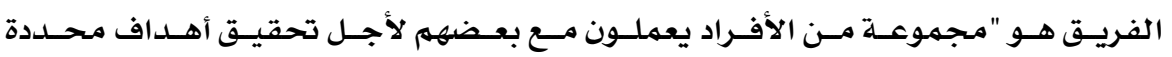

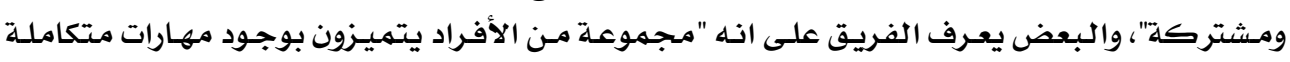

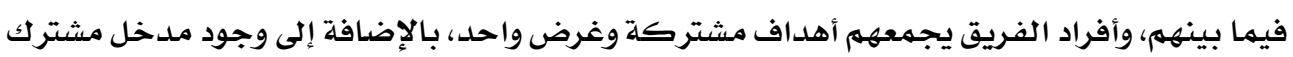

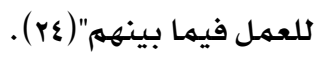

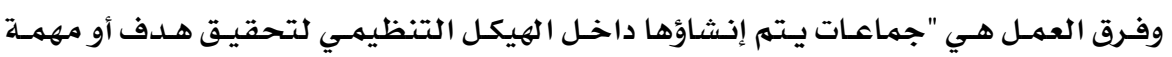

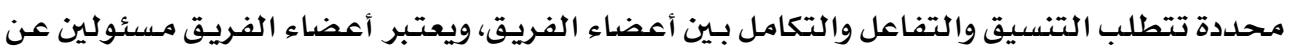

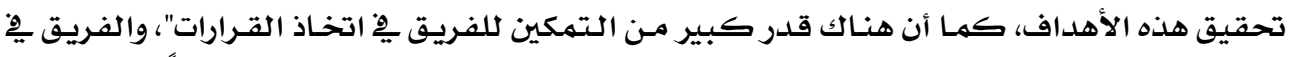

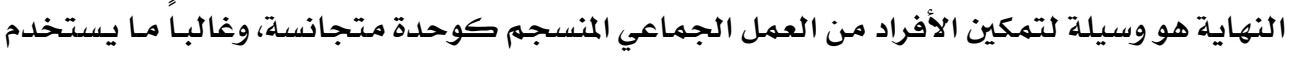

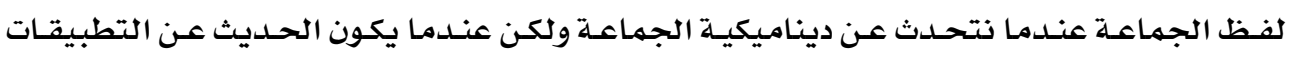

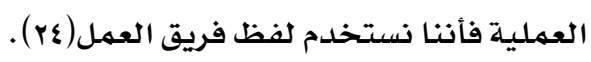

\section{مجموعات وفرق العمل:}

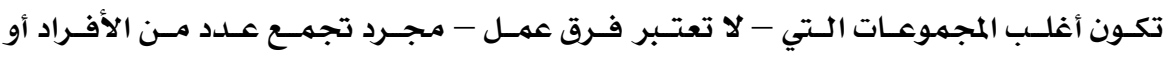

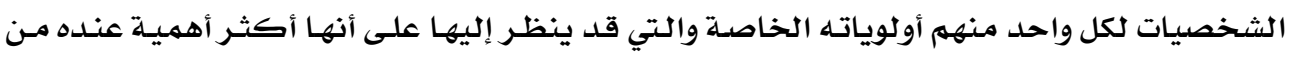

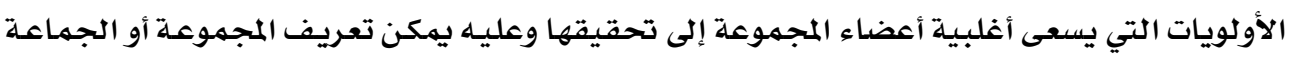

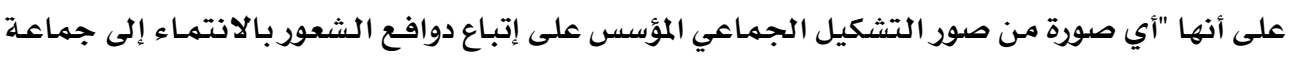

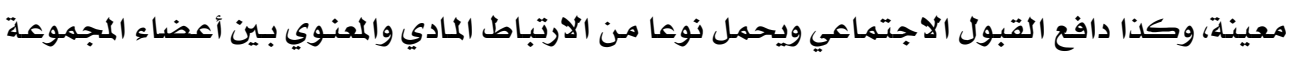

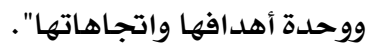

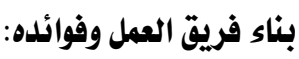

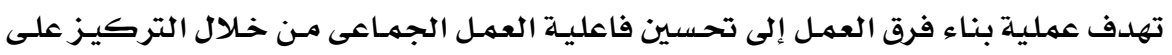

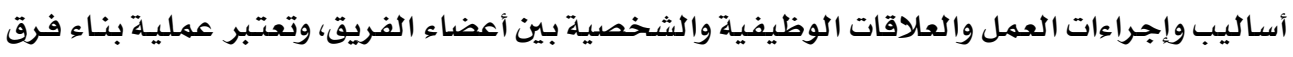




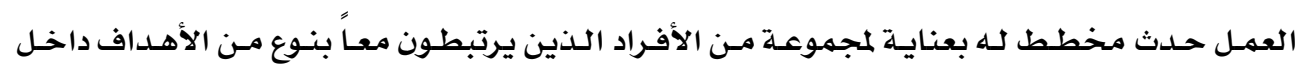

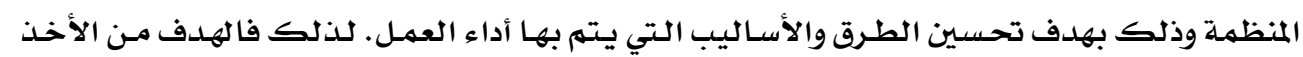

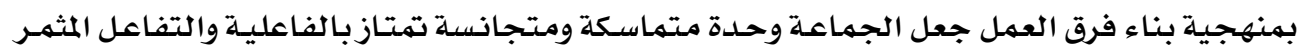

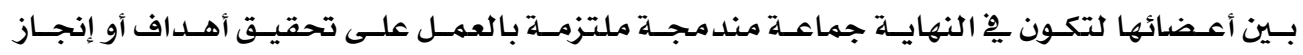

مهام مححددة.

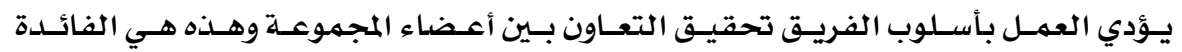

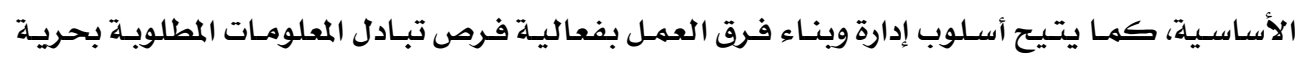

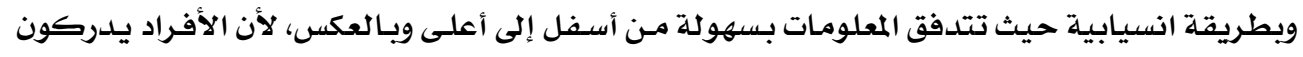

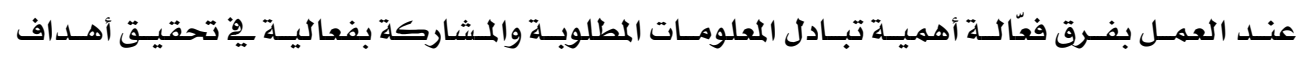
الفريق والمنظمـة.

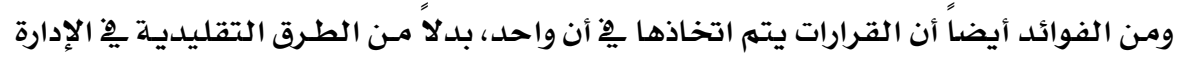

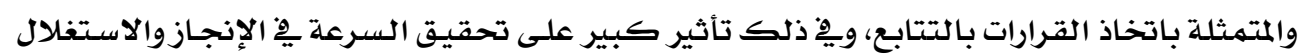

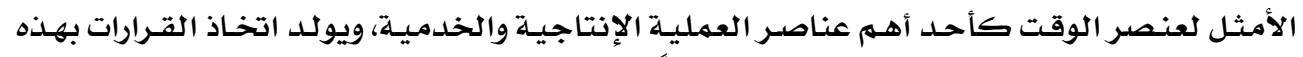

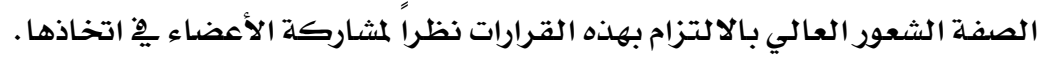

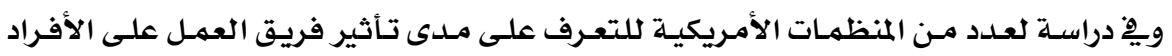

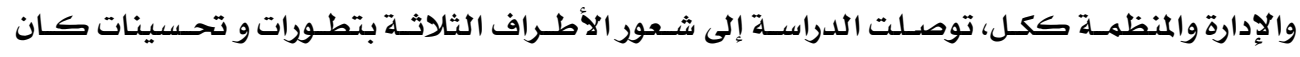

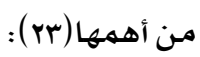

7VT٪ يرون أن فريق العمل أدى إلى تحسين معنويات أفراد الفريق.

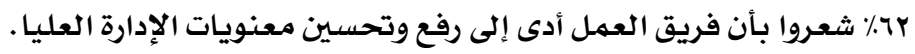

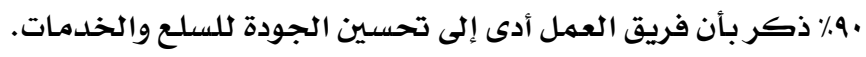

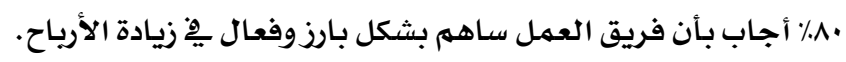

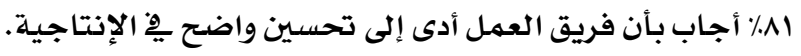

\section{خصائص فرق العمل الفعالة:}

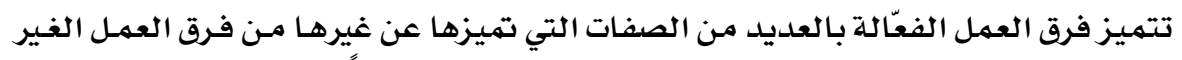

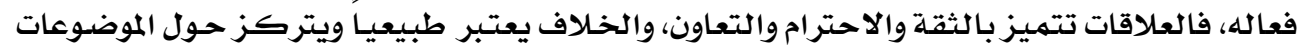

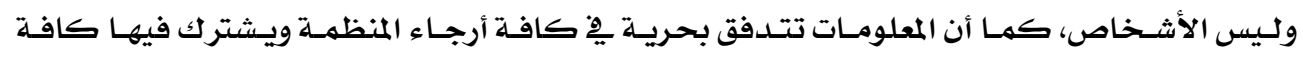

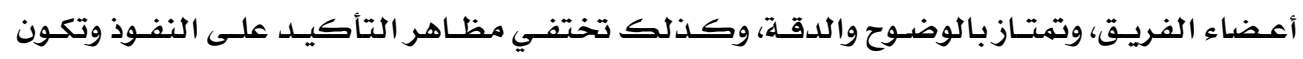

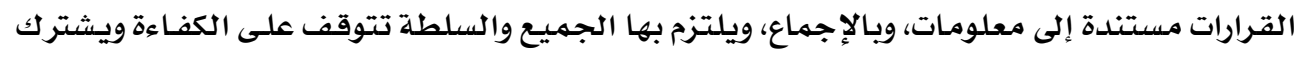

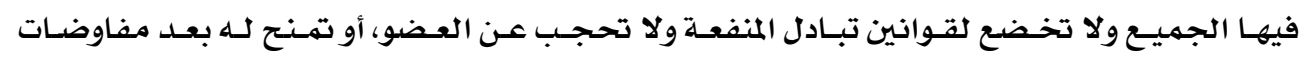

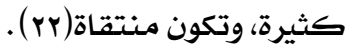




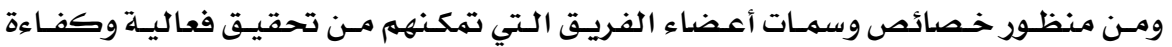

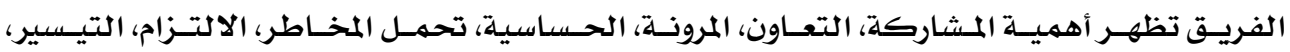
والانفتاح(r). (r).

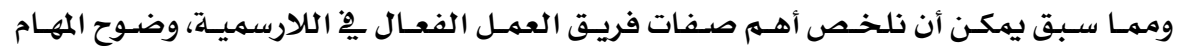

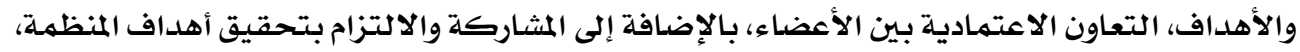

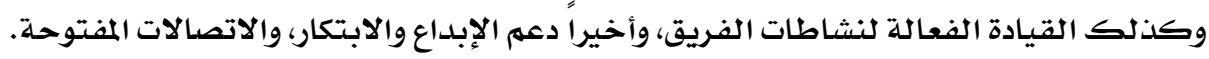

منهجية بناء فرق العمل:

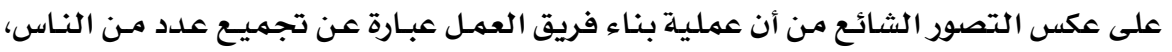

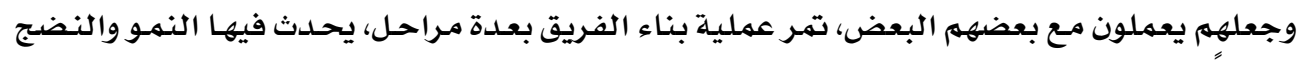

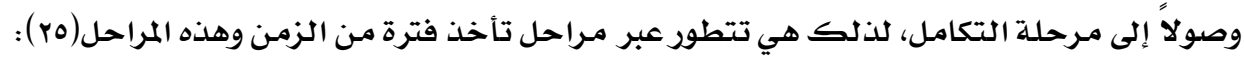

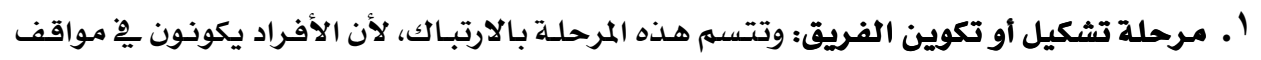

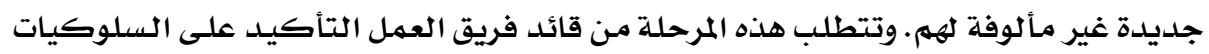

$$
\text { التي تحقق النجاح. }
$$

r ب. مرحلة الصراع: ويغلب على الأفراد يِّ هذه المرحلة الشعور بالاختلاف يِّ الآراء ووجهات النظر، وتسود سلوكيات الجدل والتنافس والصراع والدفاع عن وجهات النظر الشخراد ولئه المرحية.

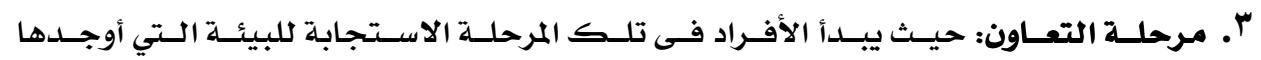
باني الفريق. ؛. مـرحلة الأداء والإنجاز: يبـدأ التزام الأفراد بهعـايير وقيم الفريق وتتسهم هـذه المرحلـة بالجديـة

$$
\text { والحيوية، والرضا عن النفس، والثقة بالآخرين. }
$$

مها تقدم يتضح أن عملية بناء وتطوير الفريق تمر بمراحل متعددة ولا تحدث عمليات البناء

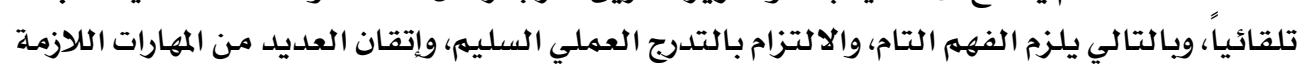

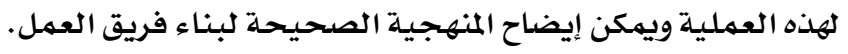

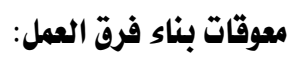

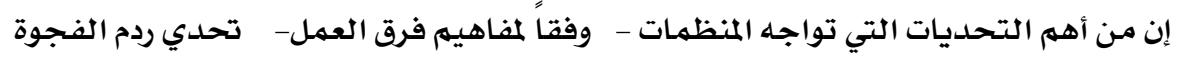

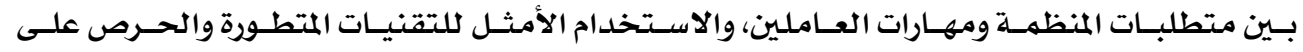

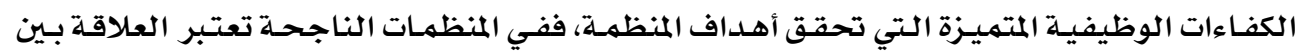

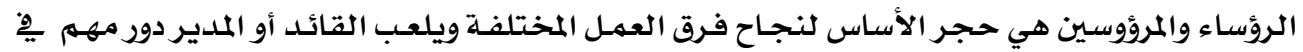

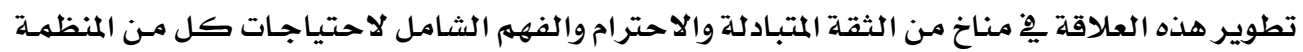

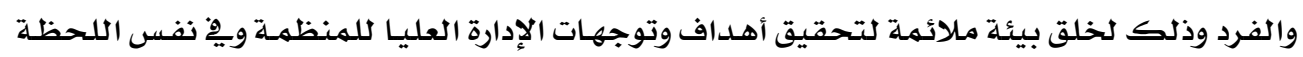


مجلة بحوث التربية النوعية - علد به - بياير $\quad$ r.18

يتتم تحقيق أهداف وتطلعات العاملين. يهكن لنا اسـتنتاج العوائق والـصعوبات التي تواجـه فـرق العهل

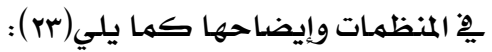

\section{المعوقات التتنظيميـة:}

ا ـ المعوقات الثقافية: ثقافة المناخ التتظيهي قد يطغى عليها ثقافة الفردية والتنافس والتركيز

$$
\text { على الإنجاز الشخصي. }
$$

Y. التركيز على إنجاز العمل: بهعنى التركيز على قبول الوظيفة كها هي والقيام بههامها بلدون النظر إلى العلاقات والمشاعر والاحتياجات الإنسانيـة للأفراد انطلاقا من قاعدة "أستطيع

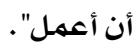

"ا. ضعف التفكير الإستراتيجي: من المعروف إن التفكير الإستراتيجي يؤدي إلى التمييز بين السبب والنتيجهة بها يساعد على تحديد المشاكل التي تواجهها المنظمهة والأسبـاب الرئيسة. فان التفكير الإستراتيجي يوفر عامل الوقت ويساعد على تحديد المهارات المطلوبة للمستويات الإداريـة المختلفة ليحول دون قيام التحصينات الثقافية المانعة لمنهجيـة بناء فرق العمل.

ك. الهيكل التتظيمي: عندما يكون هناك هيكل تقليدي ذو تسلسل هرمي واسـع يُنظر إلى بعض

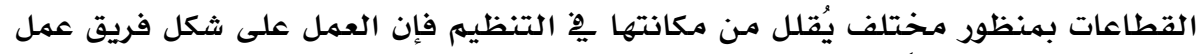
يكون عملية صعبـة جدا وتصبـح نشاطات بناء فرق العمل الفعالة غاية يِّ التعقيد. •. نظم الحوافز والمكافآت: التي تؤدي إلى التوجه للجهود الفردية مها يؤثر بشكل كبير على عمليات بناء فرق العمل وتعيق تقدمها من خلال التركيز على الفردية وإيجاد التنافس.

المعوقات الفردية:

ا ـ معتقدات قائد الفريق: تلعب معتقدات قائد الفريق واتجاهاته ومعرفته ومهاراته دوراً هاماً يِ عملية بناء الفريق حيث لا يكفي الإيمان بأهمية فرق العهل وحلده يِ بناء فرق عمل ذات فعالية عالية حيث يعود بعض القادة إلى العهل الفردي بهجررد التعرض إلى بعض الضغوط من منطلق الحرص على عامل الوقت والمحافظة على الكفاءة المطلوبة لإنجاز العمل. ץ. المهارات: المهارات الفنية ومهارات العمل ضهن الفريق، مـن المهم أن تتوافر المهارة الفنية لأعضاء الفريق بشكل كايِّ لأداء المهمة، كما أنه من المهم أن يتوفر ِِّ الفريق مهارات العمل الملائمهة ومهارات التفكير الإستراتيجي والمهارات الشخصيـة. ؟؟ . المكان: الوضـع المثالي هو أن يعمل الفريق يْ مكان واحل. ع. عدد أعضاء الفريق: يتراوح العدد المثالي لأعضاء فرق العمل عادة ما بين ثلاثة إلى ثانية أفراد ويْ بعض الأحيان يصل العدد إلى عشرة أفراد. 
ولذلك يمكن القول بأنه لا يمكن بأي حال من الأحوال بناء فريق فعال إذا كان هذا الفريق

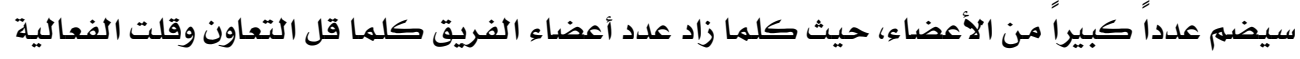

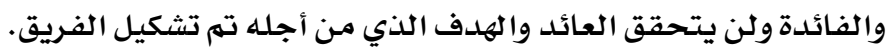

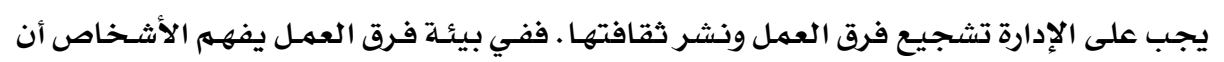

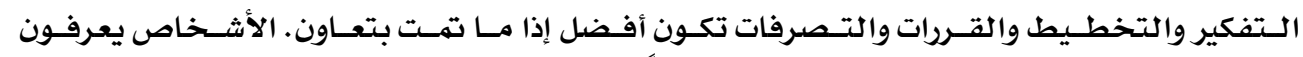

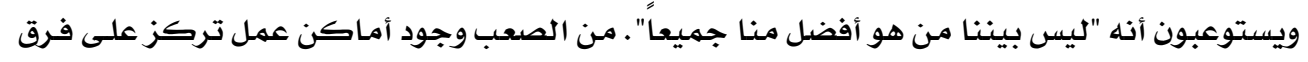

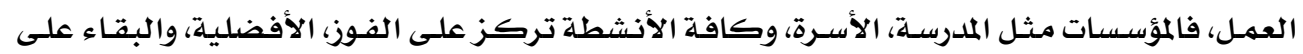

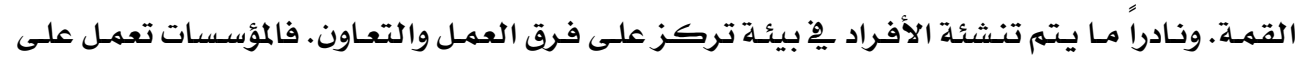

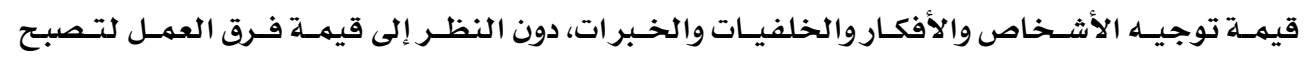
الأساس. ولتحقيق ثقافة فريق العمل يجب التأكيد على النقاط التالية|(r) :

• القادة المتميزون يجب أن يوصلوا توقعاتهم الواضحة بأن فريق العمل والتعاون آت لا محالة.

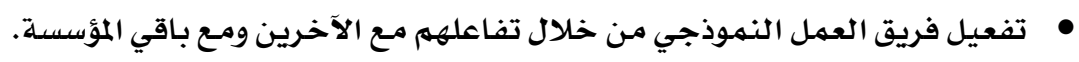

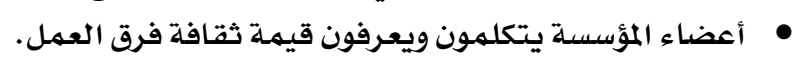

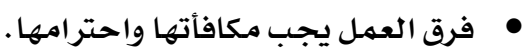

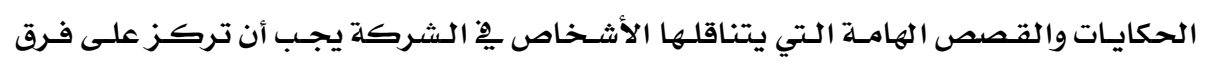
العمل. تركيز نظام إدارة الأداء على قيمة فرق العمل. وأخيراً عند الاهتمام بما سبق للقيام بمهام فرق العمل سيتحقق تقدم مذهل بِّ تحقيق ثقافة

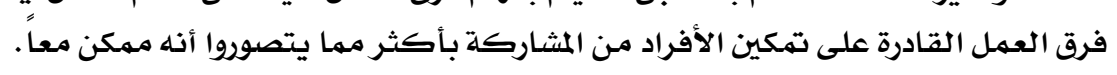

\section{1- فرق العمل في صناعة الملابس الجاهزة:}

تعتبر صناعة الملابس الجاهزة صناعة إنتاجية تجميعية حيث أنها تقدم منتجـات مفيدة ويتم

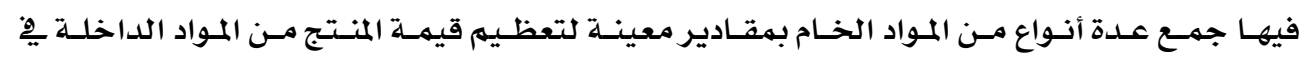

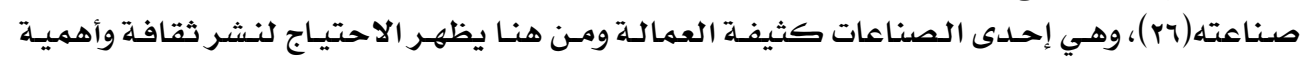
تكوين فرق العمل لتحقيق الأهداف.

تتفق نظم الجودة على أهمية العمل الجماعي وفرق العمل، فالأيزو كنظام لضمان وتهان وتوكيد

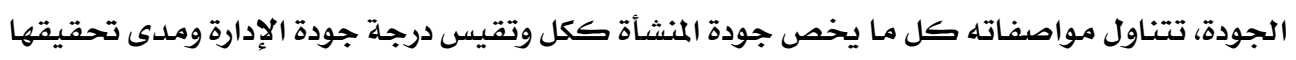

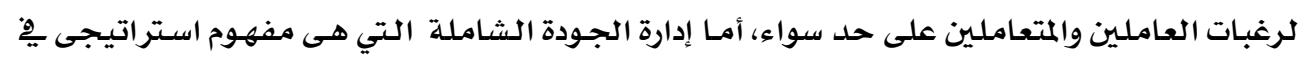

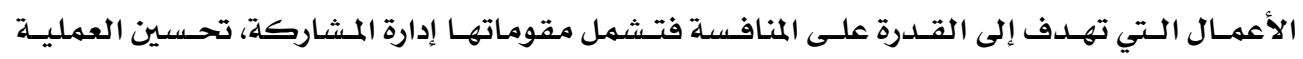

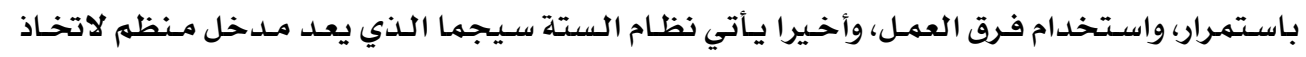

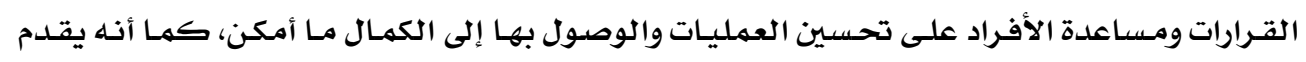

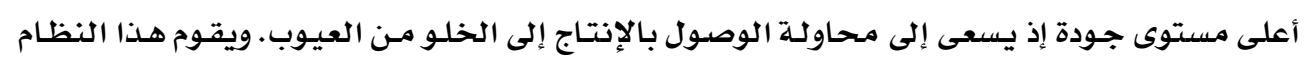


على سـتة مبـادئ رئيسية تشمل تركيـز حقيقـي وصـادق على العميـل، والإدارة بالبيانـات والحقـائق،

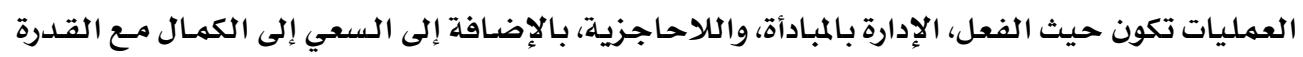

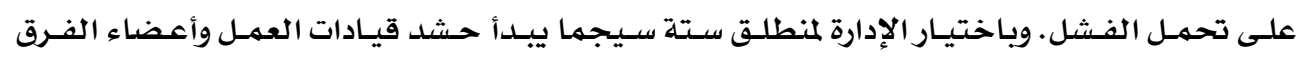

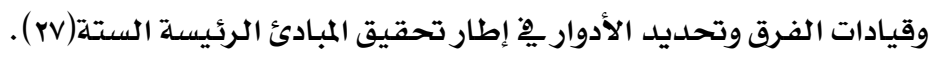

والحقيقة أنه يِّ إطار تطوير المنسوجات والملابس الذكية يتهم خلق تحديات حقيقيـة لتطبيق

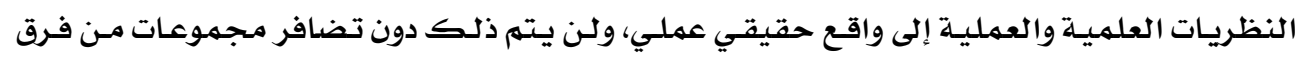

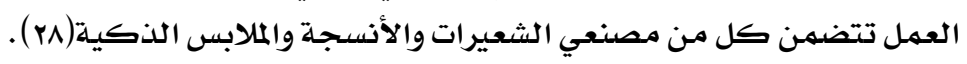
ولتحقيق كل ما سبق لابد من التأكيد على أهمية وقيمة العمل الجماعي وفرق العمل التي تتناول الخطط وتحقق من خلالها الأهداف القريبة والبعيدة المدىى ومن ثَم تتحقى التحق الغايات.

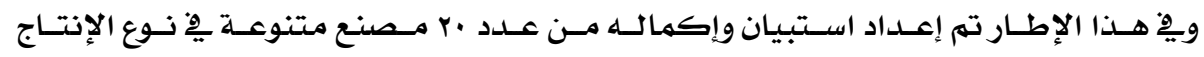

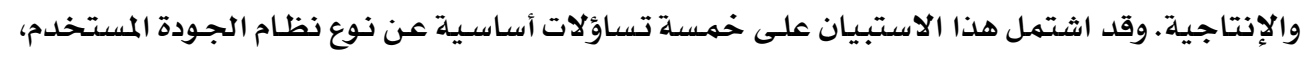

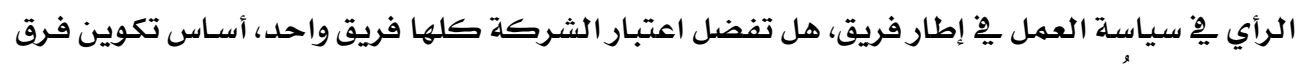
العمل، وأخيرا نوعيات تكوين فرق العمل. الأثـكال مـن (1) إلى (ه) توضـح النسب المئويـة لإجابـات مسئولي المصـانع محسل الدراسـة على

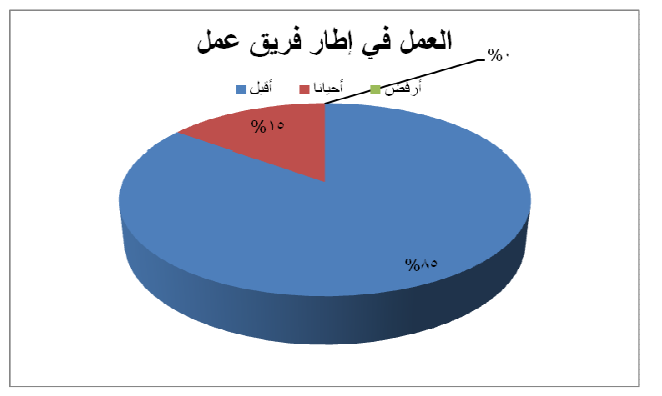

شكل (「) النسب المئوية للاستجابة بالنسبة للعمل في فريق عمل

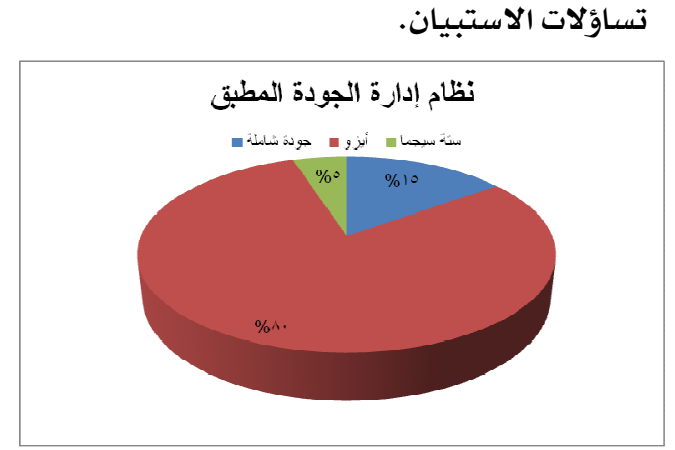

شكل (ا) النسب المئوية للاستجابة بالنسبة لنظام الجودة المطبق

يتضـح مـن شـكل (1) أن 10 ٪ مـن الشركات محسل الدراسـة تطبـق نظـام إدارة الجـودة الشـاملـة

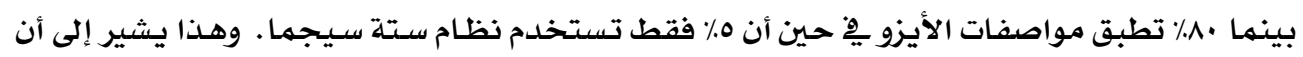

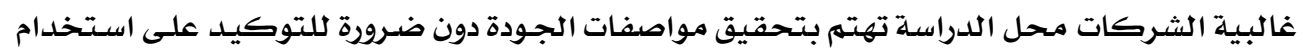
فرق العمل.

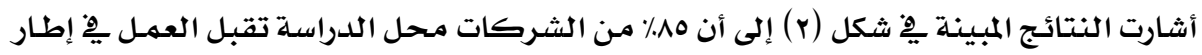

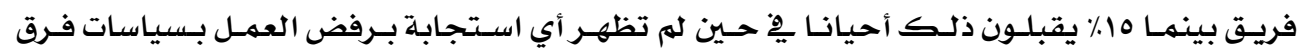

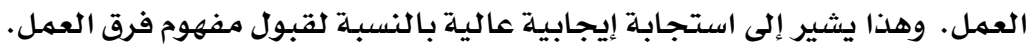




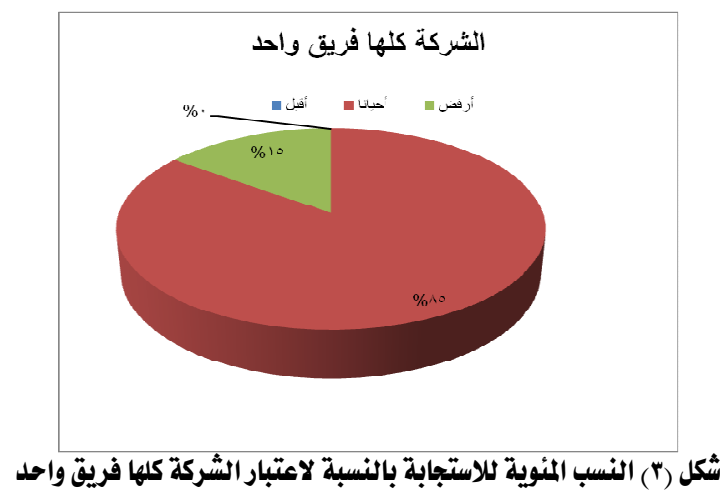

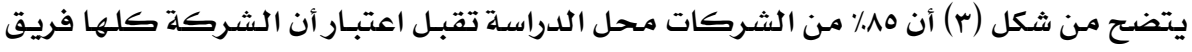

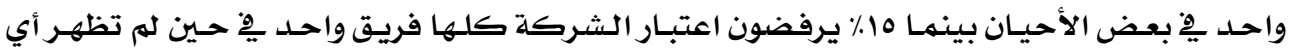

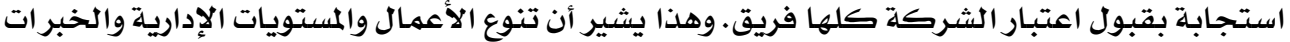
ووكذلك الثقافات تدعو إلى أهمية تقسيه الشركة إلى فرق عمل مترابطة.

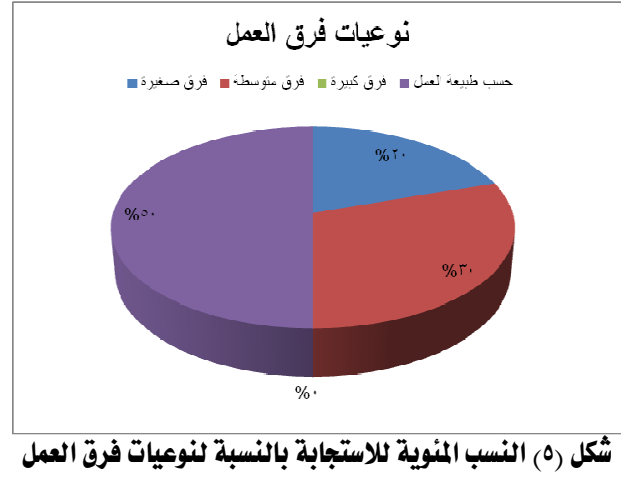

شكل (0) النسب المئوية للاستجابة بالنسبة لنوعيات فرق العمل

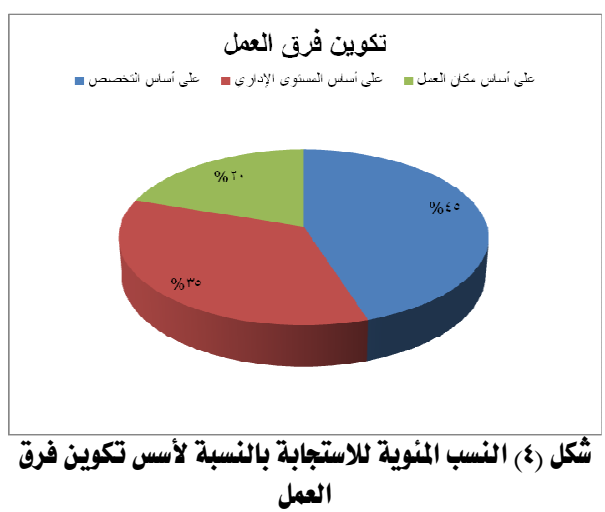
العمل

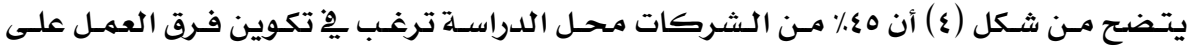

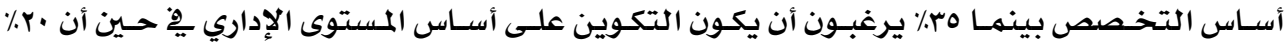

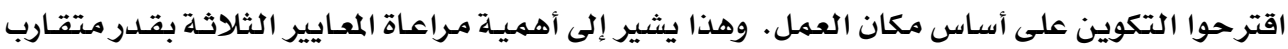
مِّْ تكوين فرق العمل.

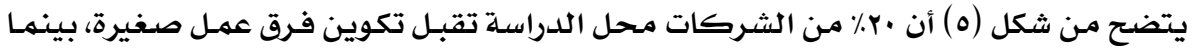

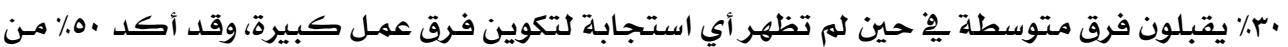

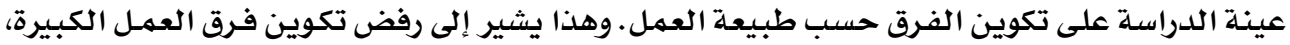

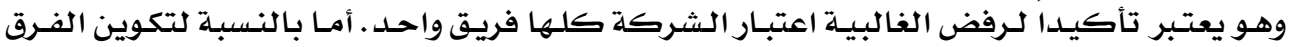

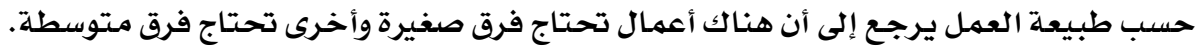


مجلة بحوث التربية النوعية - علد بr - مبناير 18

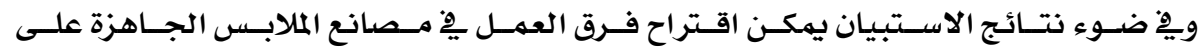

النحو التالي: و

فريق الإدارة العليا (مجلس الإدارة)

وهو الفريق المسئول عن إدارة المنشأة ويهدف إلى رفع القدارة الإدات التحات التنافسية وزيادة الريحية للمنشأة.

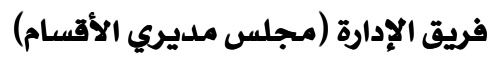

وهو المسئول الأول عن أهداف الإدارة العليا وتنفيذ آليات تحقيق الأهداف التنفيذية مِِ

$$
\text { كل قسهم. }
$$

فريق التسويق والبيع.

وهو الفريق المسئول عن تسويق المنتجات والخديقاتئدات التي تقدمها المنشأة وتحديد مستويات

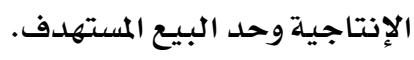

فرق التدريب والموارد البشرية.

وهي الفرق المسئولة عن تدريب وتأهيل وتنمية قدروات المبردية.

$$
\text { فريق التصميم والباترون (التصميم - الباترون). }
$$

وهو الفريق المسئول عن أعمال إعداد التصميماتيمات وباتروناتها.

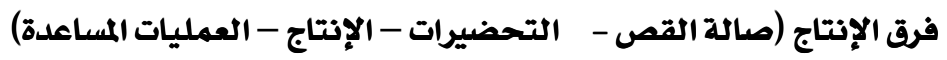

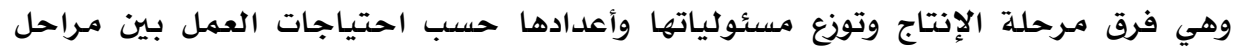

$$
\text { الإنتاج المتتوعة. }
$$$$
\text { فريق الجودة. }
$$

وهو الفريق المسئول عن تحقيق وتطبيق معايير الجودة التي تتبناها المنشأة.

فرق الصيانة (الصيانة الكهربية - الصيانة الميكانيكية - صيانة المنشآت)

وهي فرق مرحلة الصيانة وتوزع مسئولياتها وأعدادها حسب احتياجات العمل بين مهام

الصيانة المتنوعة.

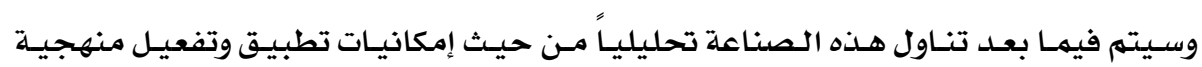

وثقافة فرق العمل. للتأكيد على أنه "معاً أفضل".

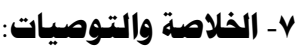

ويتضح مما سبق رُقي وأهمية تفعيل فرق العمل ِِِ كافة مناحي الحياة وقد أكد البحث على

النقاط التالية: - n

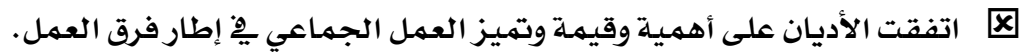

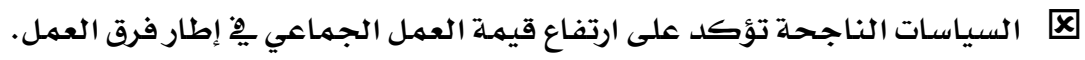


区 العملية التعليمية لا تتم إلا ِِ إطار عملية جماعية تفاعلية، ويجب التأكيد على تفعيل دور

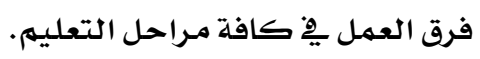

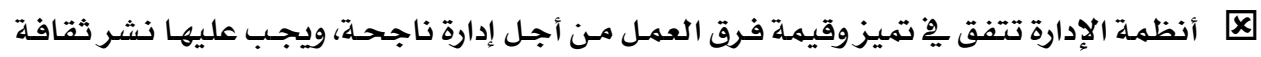

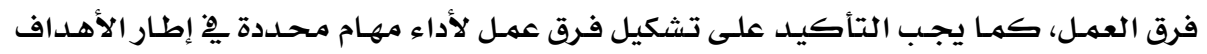

$$
\text { والغايات المرجوة. }
$$

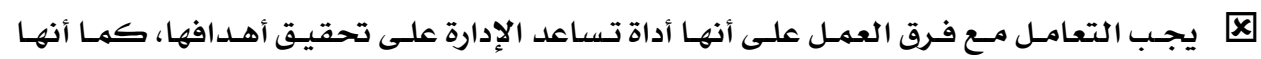

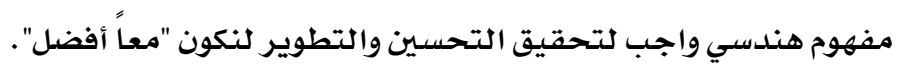

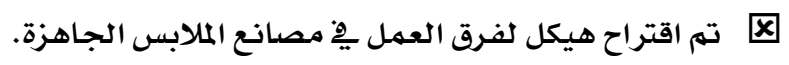

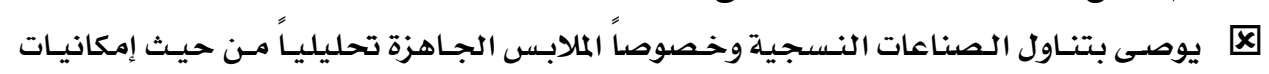

$$
\text { تطبيق وتفعيل منهجية وثقافة فرق العمل. }
$$

شكر وتقدير:

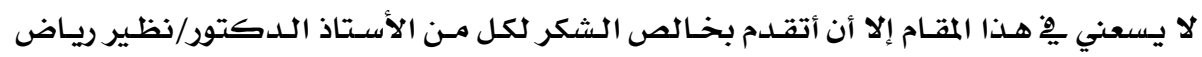

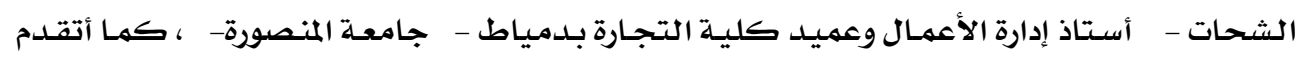

بالشكر للقس يُسطس القس بكاتدرائيـة مـاريولس بطنطا، وكذلك الشيخ/ أحمد الحسيني المداح

إمام وخطيب مسجد المصطفى بطنطا على تعاونهم الصادق . ولهم مني خالص الشكر والتقدير.

: المراجع

1. Webster's New World Dictionary and Thesaurus, $2^{\text {nd }}$ Edition, by Editors of Webster's New World Dictionaries, Charlton Laird, May 2002.

2. http://www.muslim-programers.com/3/teamwork.htm (Mar/2011)

3. http://humanresources.about.com/od/involvementteams/a/team_culture.htm (Mar/2011)

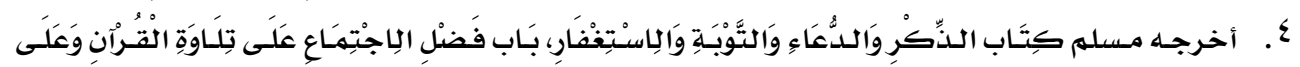

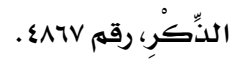

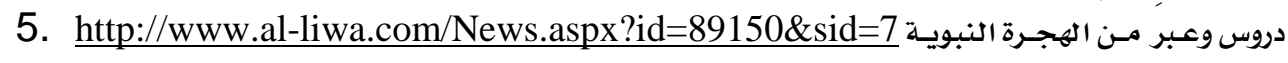
$r \cdot 1 \cdot / 1 r / \cdot v$

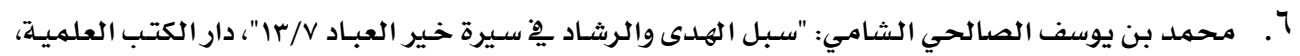

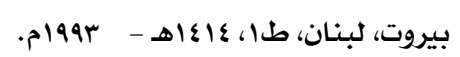

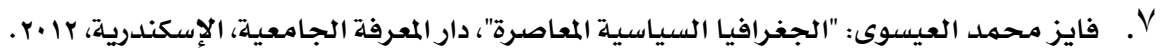

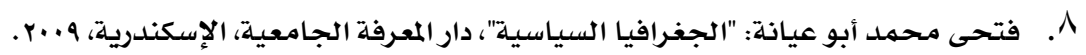


9 . . حازم الببلاوى: "دور الدولة فى الاقتصاد"، الهيئة المصرية العـامـة للكتاب، القاهرة، 1999. 10. http://www.ndt-ed.org/TeachingResources/ClassroomTips/ Teamwork.htm ا 1 ـ سـالم بن على القحطـى : "فاعليـة التعلم التعـاونى فى تحصيل الطلاب وتنميـة اتجاهـاتهم فى الدراسـات

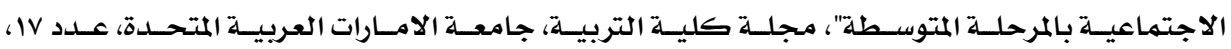
ص.... ب ا ـ خميس مححمد خميس: "استراتيجيـات التعلهم التعـاونى وتدريس الدراسـات الاجتماعيـة"، القـاهرة، العربيـة

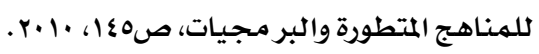

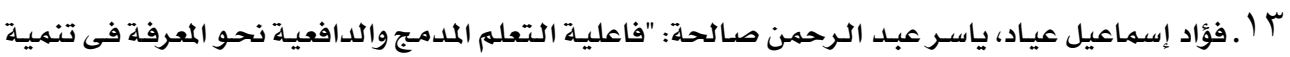

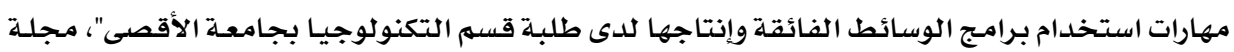

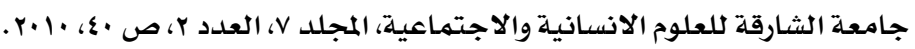

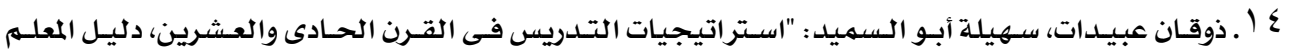

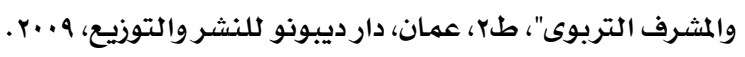

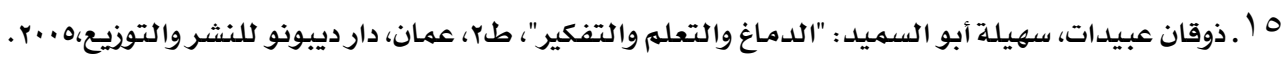

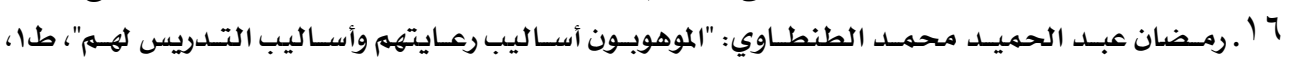

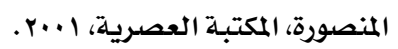

IV . يوسف سعلد "فاعلية العصف الذهنى فى تنهيـة مهارات التفكير الإبـاعى دراسـة تجريبيـة على عينـة مـن

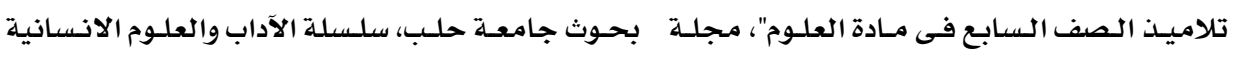

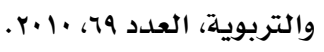

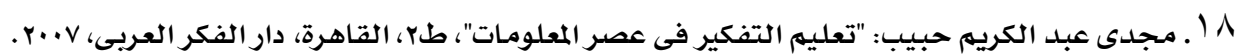

19. James H. Donnely, Jr., James L. Gibson, John M. Ivancevevich, "Fundamentals of Management" Irwin/McGraw-Hill, USA, 1998.

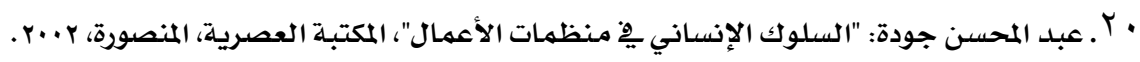

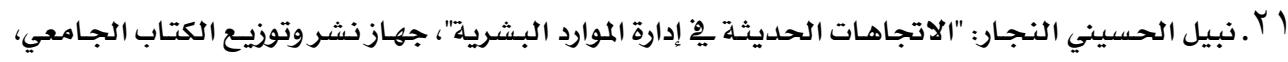

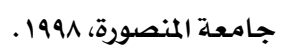

Y Y . جاد الرب عبد السميـع: "مؤشـرات تغييرات الهياكل التنظيمية بـالاعتماد علي منهجيـة فرق العمل : دراسـة

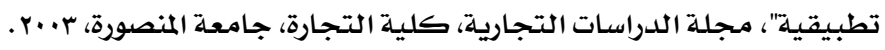

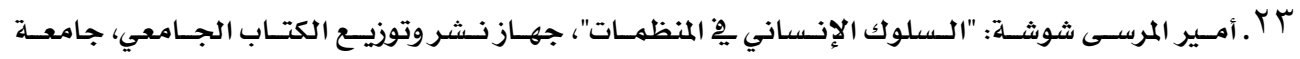

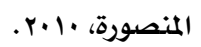

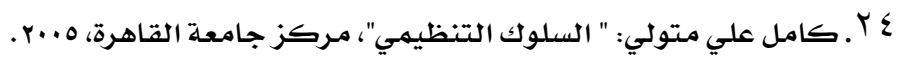

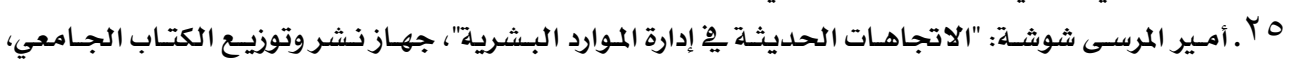

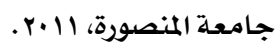

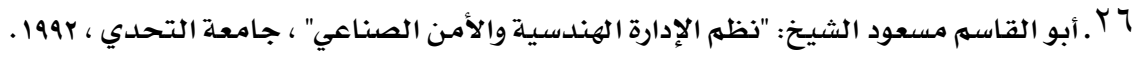




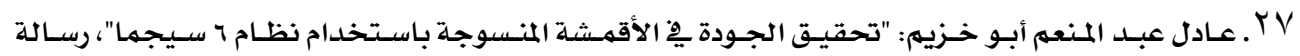

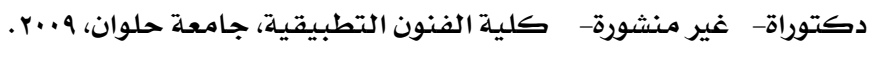

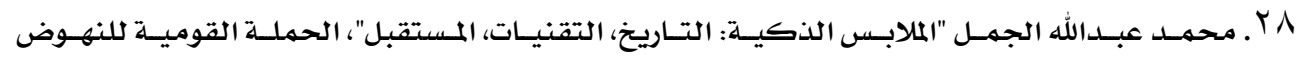

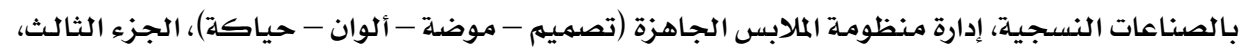

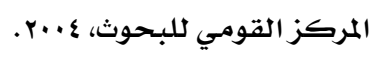




\section{IMPORTANGE AND APPLIGATION OF TEAM WORKING IN VARIABLE FIELOS TO ACHIEVE PERFECT PERFORMANCE}

\section{Abstract}

Teamwork is defined as "a joint action by a group of people, in which each person subordinates his or her individual interests and opinions to the unity and efficiency of the group" This does not mean that the individual is no longer important; however, it does mean that effective and efficient teamwork goes beyond individual accomplishments. The most effective teamwork is produced when all the individuals involved harmonize their contributions and work towards a common goal.

Religion men, politics, artists, and sportsmen agreed that every succeed work can't be done individually; things are to be done by groups through teamwork spirit. Policy, sport, art, science, all life affairs be more successful if done with team spirit.

The aim of this work is to insure the importance $\&$ advantages of team working to help our country achieving the best goals. We are going to present -briefly- the importance of team working through religion, policy, education, and management, as life affairs, without ignoring other affairs like science, arts, sports, etc.

The results showed that team working is very important through life affairs, so we have to insure, creation and improving the culture of team working -not committee and subcommittee- to fulfill specific tasks through objectives and goals required to be distinguish. Team working must be considered as a tool helping management to fulfill objectives, and an obligatory engineering concept to fulfill improvement and development to be better together. 